Portland State University

PDXScholar

1982

\title{
One-third octave band augmented speech discrimination testing for normal hearing listeners
}

Nancy Marie Bowen

Portland State University

Follow this and additional works at: https://pdxscholar.library.pdx.edu/open_access_etds

Part of the Cognition and Perception Commons, and the Speech and Hearing Science Commons Let us know how access to this document benefits you.

\section{Recommended Citation}

Bowen, Nancy Marie, "One-third octave band augmented speech discrimination testing for normal hearing listeners" (1982). Dissertations and Theses. Paper 3160.

https://doi.org/10.15760/etd.3145

This Thesis is brought to you for free and open access. It has been accepted for inclusion in Dissertations and Theses by an authorized administrator of PDXScholar. Please contact us if we can make this document more accessible: pdxscholar@pdx.edu. 
AN ABSTRACT OF THE THESIS OF Nancy Marie Bowen for the Master of Science in Speech Communication presented February 26, 1982.

Title: One-Third Octave Band Augmented Speech Discrimination Testing for Normal Hearing Listeners.

APPROVED BY MEMBERS OF THE THESIS COMMITTEE:

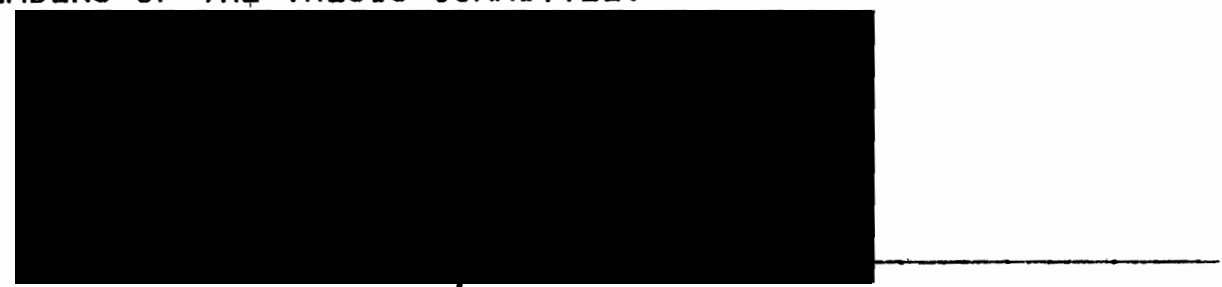

Alamander Hicks, Ph.D., Chairman

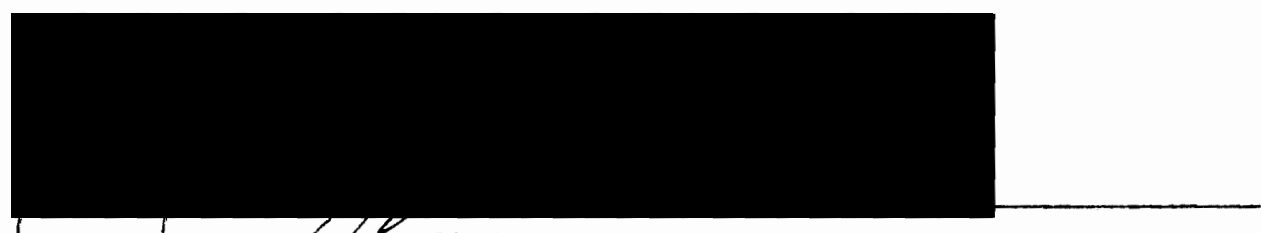

James F. Mauper, Ph.D.

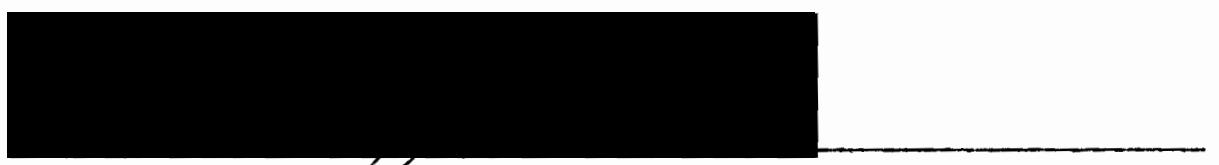

Robert E. Jones, Ph.D.

The purpose of this study was to investigate the effects of a $500 \mathrm{~Hz}$ and $3150 \mathrm{~Hz}$ one-third octave band augmentation on the speech discrimination ability of normal hearing listeners and whether such effects vary with signal presentation level. The augmented portion of monosyllabic words was systematically varied from 5-55dB above the 
intensity level of the unfiltered version of the words and presented simultaneously to one ear.

The present investigation revealed that both the $500 \mathrm{~Hz}$ and $3150 \mathrm{~Hz}$ augmented speech tests precluded perfect discrimination scores in a normal hearing population. The small standard deviations observed in the $3150 \mathrm{~Hz}$ augmented condition, regardless of presentation level, suggested that this test may have clinical potential as a diagnostic test. The $500 \mathrm{~Hz}$ augmented condition produced a rollover in discrimination ability with increasing intensity disparity level.

It was concluded that the reduced discrimination scores observed in the two augmented conditions were the result of a combination of frequency and intensity distortion, with frequency playing the dominant role. Further, the low frequency distortion component appeared to have a more deleterious effect on speech discrimination ability. 
ONE-THIRD OCTAVE BAND AUGMENTED SPEECH DISCRIMINATION TESTING FOR NORMAL HEARING LISTENERS

by

NANCY MARIE BOWEN

A thesis submitted in partial fulfillment of the requirements for the degree of

\section{MASTER OF SCIENCE}

in

SPEECH

with emphasis in Speech Pathology

and Audiology

Portland State University 
TO THE OFFICE OF GRADUATE STUDIES AND RESEARCH:

The members of the Committee approve the thes is of Nancy Marie Bowen presented February 26, 1982.
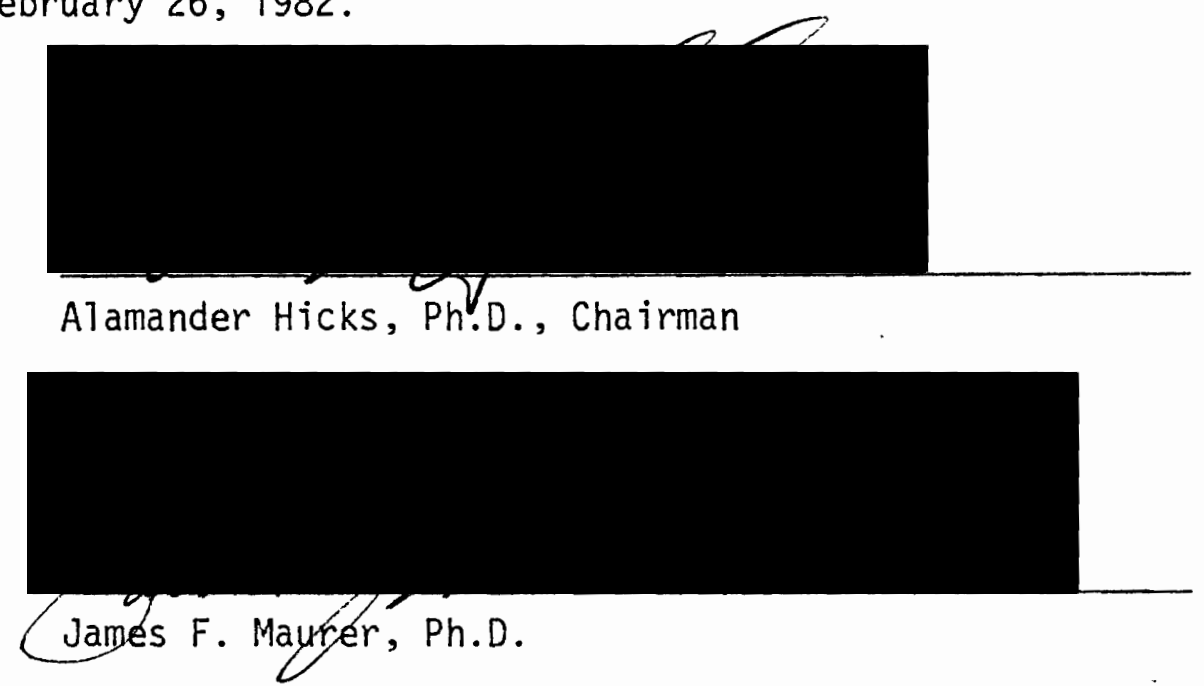

\section{APPROVED:}

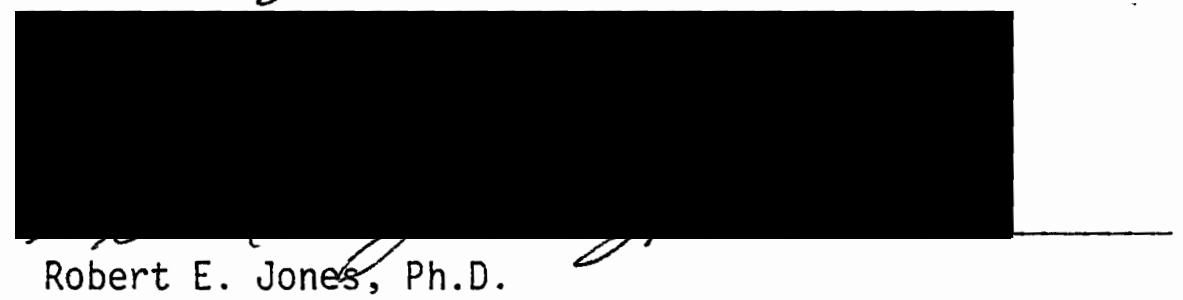

Theodore G. Grove, Head, Department of Speech Communication

Stanley E. Rauch, Dean of Graduate Studies and Research 
In Dedication and Love to My Parents 


\section{ACKNOWLEDGEMENTS}

The completion of this project has required the time and assistance of several individuals, all of whom I owe my sincerest appreciation.

To Dr. Al Hicks, my advisor, key instructor and thesis committee chairman, I offer my deepest gratitude. With his knowledge of research, expertise with the equipment and attention to details, he provided me the technical assistance I needed to develop a viable research study. With his unremitting encouragement, support and time, he gave me the impetus to complete a very long and tedious project. His dedication to teaching and to audiology has been invaluable.

I also extend my gratitude to Dr. James Maurer, who provided the foundation for this investigation. His advice and support were appreciated not only during this research but throughout my graduate years.

I would like to thank Dr. Robert Jones, who took time from a very busy schedule to be a part of my thesis committee from the start. His willingness to provide input to this research certainly facilitated its completion.

For their expert advice in statistics and research design, I would like to thank Dr. Ted Grove and Dr. Jim Paulsen. Through their instruction, I was able to perform my own statistical analysis as well as the interpretation of the results!

Finally, I wish to thank the several students who volunteered their time to participate in this investigation. Their patience, interest and curiousity made this project a very enjoyable experience for me. 


\section{TABLE OF CONTENTS}

PAGE

DEDICATION . . . . . . . . . . . . . . . . . . ACKNOWLEDGEMENTS ..................... iv LIST OF TABLES ....................... . vi LIST OF FIGURES ..................... . . vij CHAPTER

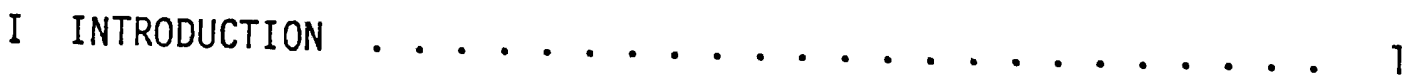

II REVIEW OF LITERATURE . . . . . . . . . . . . . . 4 DISTORTED SPEECH TESTING ................ 4

Frequency Distortion ............ 5

Intensity Distortion ............. 21 PURPOSE ....................... 29

III METHODS ...................... 30

Subjects................. 30

Procedure ............... 30

Instrumentation ............ 34

Calibration ................... 37

IV RESULTS ........................ 38

$\checkmark$ DISCUSSION AND CONCLUSIONS ............. . . 44

Implications for Further Research ..... . . 47 


\section{LIST OF TABLES}

TABLE

PAGE

I Comparison of Discrimination Scores Obtained from Low-

Pass Filtered Meaningless Syllables, Monosyllabic Words and Both Familiar and Unfamiliar Words . . . . 12

II Comparison of the Mean Percent Correct Scores For Monosyllabic Words Filtered Through Various Band-Pass Systems ................. . . 14

III Comparison of the Mean Percent Correct Scores and Standard Deviations for the $500 \mathrm{~Hz}, 3150 \mathrm{~Hz}$ and Unfi7tered Augmented Experimental Conditions at Each of the Six Intensity Presentation Levels . . . . . . 40

IV The Mean Percent Correct Scores and Standard Deviations According to Order of Presentation for Each of the Three Augmented Experimental Conditions . . . . . 43 


\section{LIST OF FIGURES}

FIGURE

PAGE

1. Relationship of the Auditory Pathway Progressing From

the Peripheral Mechanism Through the Central

Nervous System . . . . . . . . . . . . . 2

2. Frequency Response Plots of Low-Pass, High-Pass and Band-Pass Filters . . . . . . . . . . . 6

3. Maximum Discrimination for Syllable Articulation for Low- and High-Pass Filter Conditions as Related to Cut-Off Frequency .. . . . . . . . . . . 7

4. Effect of Low- and High-Pass Filtering on the D-iscrimination of Meaningless Syllables . . . . . . . 9

5. Idealized Functions of the Relations Between Articulation Score and the Cut-Off Frequency for Lowand High-Pass Filtering . . . . . . . . . 10

6. A Comparative Representation of Intelligibility Scores

Obtained Utilizing Narrow-Band Filtering . . . . . 16

7. Average Discrimination Scores for Filtered Voice in

the Homolateral vs. Contralateral Ears . . . . . 18

8. Performance-Intensity Functions for Persons With Normal

Hearing, Cochlear Hearing Loss and Eighth Nerve Damage . . . . . . . . . . . . . . . 23

9. Schematic for Recording One-Third Octave Band Augmentation ................ 35 


\section{CHAPTER I}

\section{INTRODUCTION}

Human audition involves several stages of processing, with the initial analysis occurring in the auditory periphery. Subsequentiy, the peripheral output is processed through an intricate network of neural pathways, to be ultimately synthesized in the auditory cortex. Determination of the locus of pathology within the auditory system becomes increasingly complex as the site of lesion progresses from the peripheral ear to the central nervous system (Jerger, 1960). See Figure 1. Audiometric manifestation of a lesion becomes more subtle as one moves toward the cortex (Jerger, 1960); consequent7y, responses to intensity and frequency become less definitive (Bocca and Calearo, 1963). While peripheral disorders which produce hearing loss may be identified with simple pure tone stimuli, the differentiation of neural degeneration requires more complex auditory tasks (Jerger, 1964; Bocca, 1967; Snow, et al., 1977).

Human speech, while considered to be acoustically and temporally complex, bears with it an extrinsic redundancy, or internal structuring, based upon the replication of phoneme (speech unit) information (Paiva, 1965; Korsan-Bengtsen, 1973; Lundborg, et a1., 1975; Snow; et a1., 1977; Stevens, 1978). That is, ordinary speech provides more information to the listener than is necessary for the perception of a message. This extrinsic redundancy of speech often allows recognition of a message on 


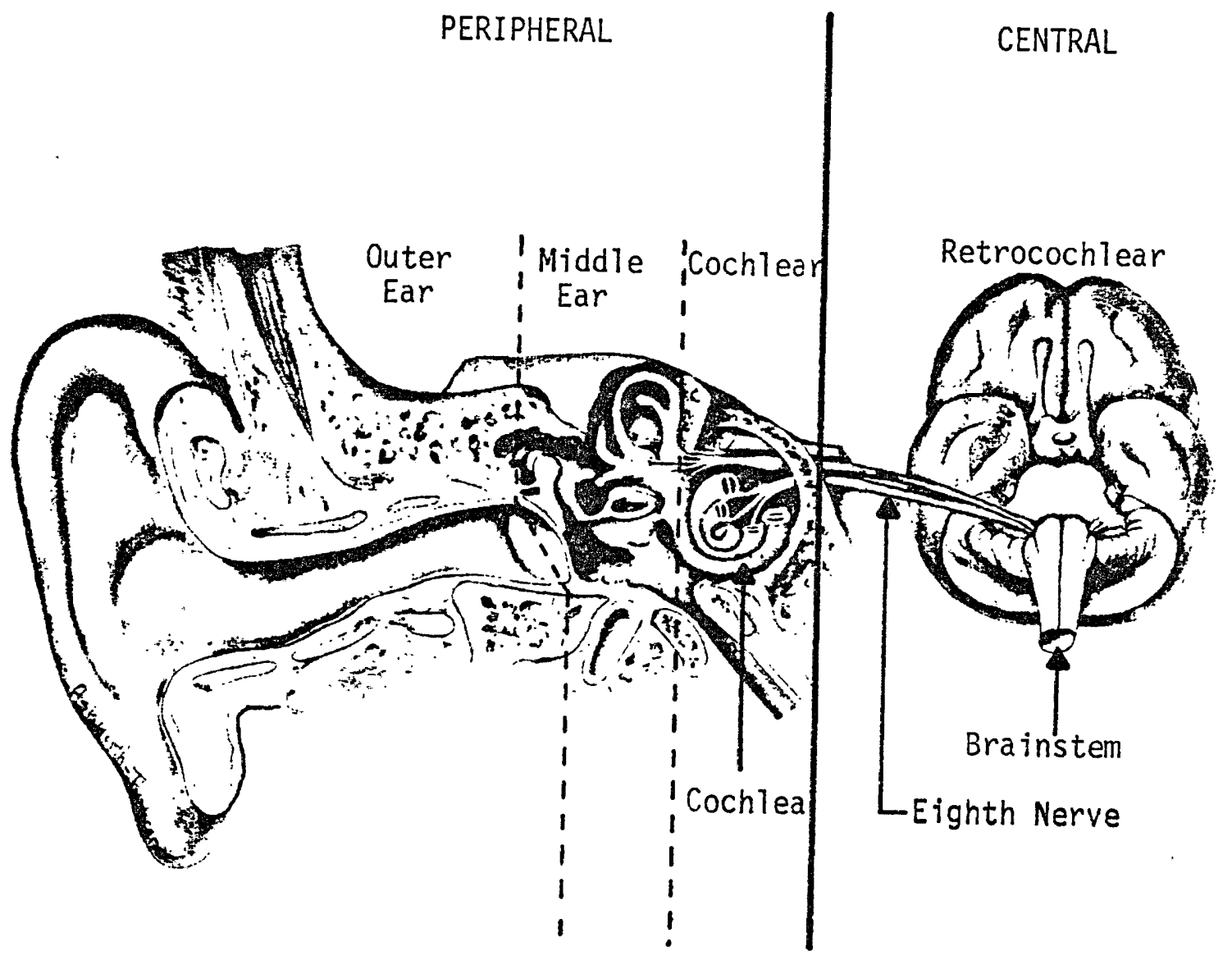

Figure 1. Relationship of the auditory pathway progressing from the peripheral mechanism through the central nervous system (After
Jacobs and Francone, 1970). 
the basis of a single distinctive component. Thus, the loss or distortion of some individual speech elements by the receiver does not necessarily imply that the entire message will be unintelligible or misinterpreted (Lundborg, et a1., 1975).

Furthermore, the multiplicity of neural fibers and connections which characterize the central auditory pathways provides an intrinsic redundancy for the incoming signal (Bocca and Calearo, 1963; Palva, 1965; Lundborg, et a1., 1975; Snow, et a1., 1977). The abundance of neural structures allows the central auditory system to perceive and identify patterns of incoming phonemes and words with a different outline for each message. Since the central auditory system is capable of integrating the patterns of a message, a whole speech message may be efficiently recognized even when it lacks one or more constituents (Bocca, 1967; Lundborg, et a 1., 1975).

It is not surprising then, that simple auditory discrimination tasks fail to define central lesions (Snow, et a1., 1977). Due to the high extrinsic redundancy of conventional speech materials coupled with the inherent intrinsic redundancy of the central auditory pathways, lesions in the brainstem and auditory cortex elude detection. That is, given normal peripheral hearing, the central auditory system is not sufficiently taxed when traditional speech materials are employed for auditory testing (Bocca, 1967; Jerger, 1973; Korsan-Bengtsen, 1973; Snow, et a1., 1977). Conventional speech discrimination testing therefore remains futile in the identification of central auditory disorders. 
CHAPTER II

\section{REVIEW OF THE LITERATURE}

Tests which variously degrade or distort speech stimuli, thereby reducing extrinsic redundancy, have been reported to indirectly assess the integrity of the central auditory pathways (Bocca, et al, 1955; Carhart, 1965; Bocca, 1967; Korsan-Bengtsen, 1973; Lundborg, et a1., 1975; Snow, et al., 1977). That is, the loss of extrinsic redundancy produces similar effects on speech perception as reduced intrinsic redundancy. Consequently, it is possible to compare the problems of speech recognition when the internal redundancy of speech is reduced, as in certain central lesions, with problems resulting when the external redundancy is reduced by intentionally distorting speech stimuli. While distorted speech results in reduced speech discrimination performance in normal as well as hearing impaired 1 isteners, the effect is

more dramatic in persons with central auditory pathologies. This finding may be explained by a dual reduction in redundancy, intrinsic and extrinsic, in individuals with lesions of the central auditory tracts (Bocca, 1967; Lundborg, et a1., 1975; Snow, et a1., 1977).

\section{DISTORTED SPEECH TESTING}

Speech signals may be made less redundant by intentionaliy distorting their frequency (pitch) or intensity (loudness) parameters. Since both the frequency and intensity of speech are evident features in 
single words as well as ongoing discourse, the physical manipulation of these parameters has undergone a great deal of research. For the most part, the following discussion will be based upon investigations utilizing single word stimuli in distorted speech testing.

\section{Frequency Distortion}

Speech can be degraded by eliminating a portion of the frequency spectrum through electronic filtering. For example, a low-pass filter will pass only frequencies below a certain cut-off frequency, thus el iminating the higher frequency acoustic information normally present for the understanding of a spoken message. The amount of distortion depends upon the cut-off frequency $(\mathrm{Hz})$ and the filter rejection rate (dB/octave), or rate at which the filter attenuates frequencies above and/or below the cut-off frequency. Low-pass, high-pass and various band-pass filtered conditions (Figure 2 ) have been utilized in speech discrimination experiments in an effort to: 1) assess the effectiveness of communications equipment, 2) simulate in normal hearing listeners the effects of various hearing impairments (Hirsh, et a1., 1954; Danhauer, et al., 1977) and 3) reduce the extrinsic redundancy of speech stimuli, thereby taxing the central auditory pathways (KorsanBengtsen, 1973; Snow, et a1., 1977).

Working with the Bell Telephone Laboratories, French and Steinberg (1947) developed a graph or an "articulation index" for the purpose of illustrating the effects of varying amounts of filtering on speech discrimination ability. According to their data, the optimum presentation level was approximately $55 \mathrm{~dB}$ HL for meaningless syllables under conditions of low-pass or high-pass filtering. Figure 3 illustrates the 

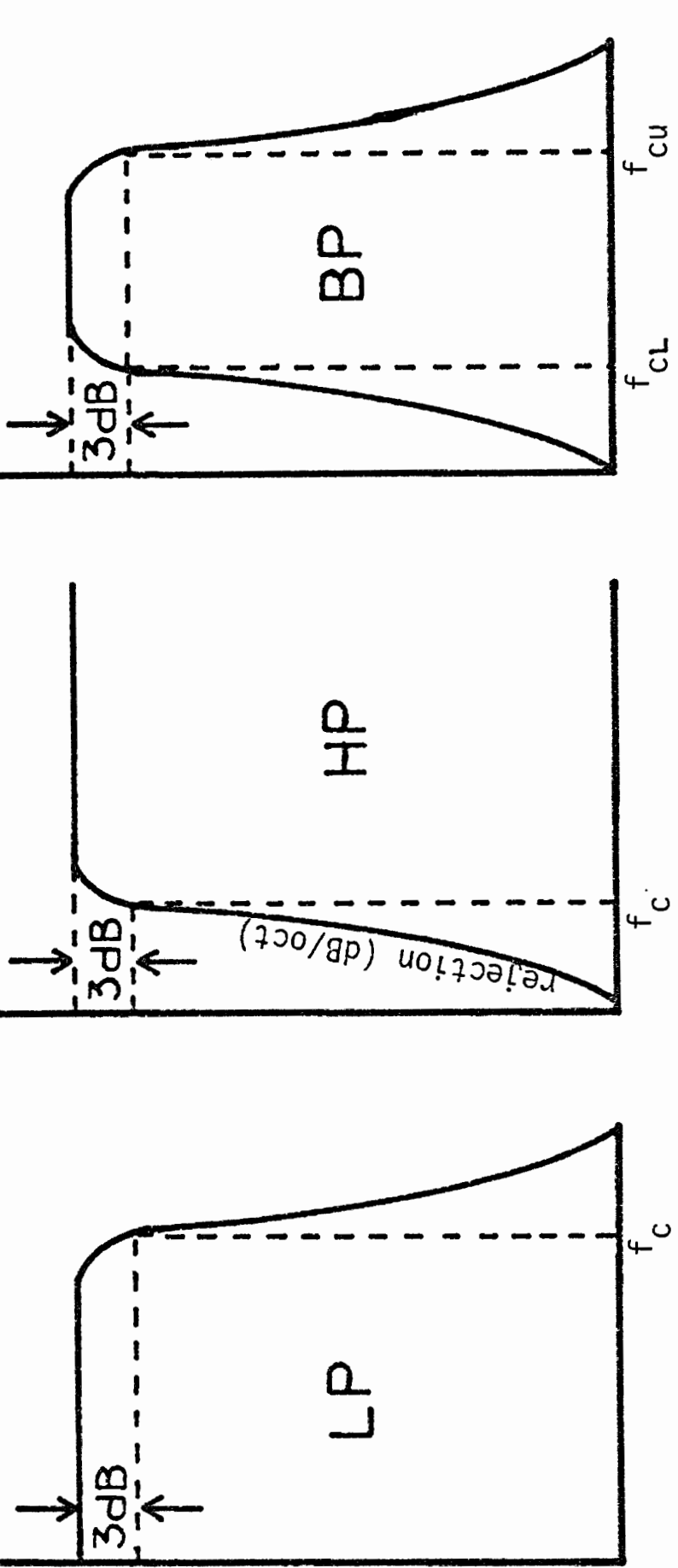

돔

을

ज过

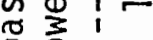

은

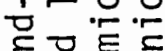

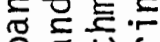

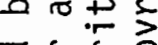

을 文

ro

윽으몯

수워

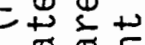

ก

的

ర등

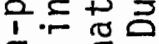

ร.

요

E4 的

당 出

ลโธิ

$\exists$ 도

U잉

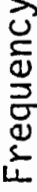

ज4

跤

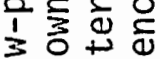

호요원

- क 4 व पै 2 का 구용 잉 a

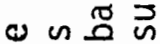
जी 눙워 음 ¿ वफ ओर

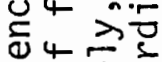
340

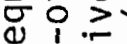
站

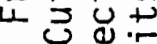
-1 든 vi is

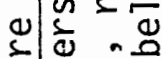

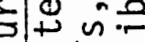

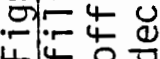




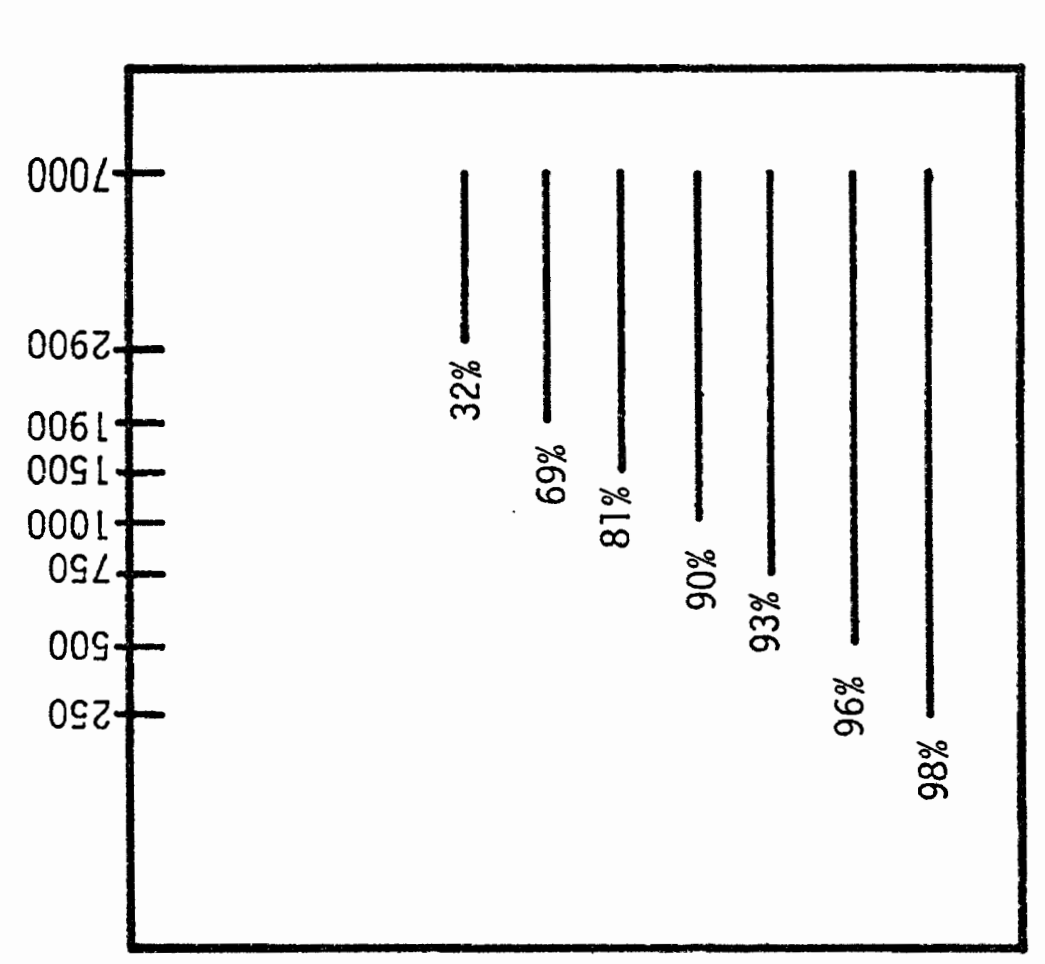

c)

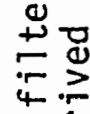

थ

$\sim 0$

잉

ڤ

t $\leq \omega_{4}$

드 巳

\#

Ð

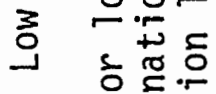

ज 4 है⿴囗十

更

요 $+\infty$

드 흥 婇是

$+1$

\% 0

$\stackrel{0}{0}$

응 Ð

$=2$

जे

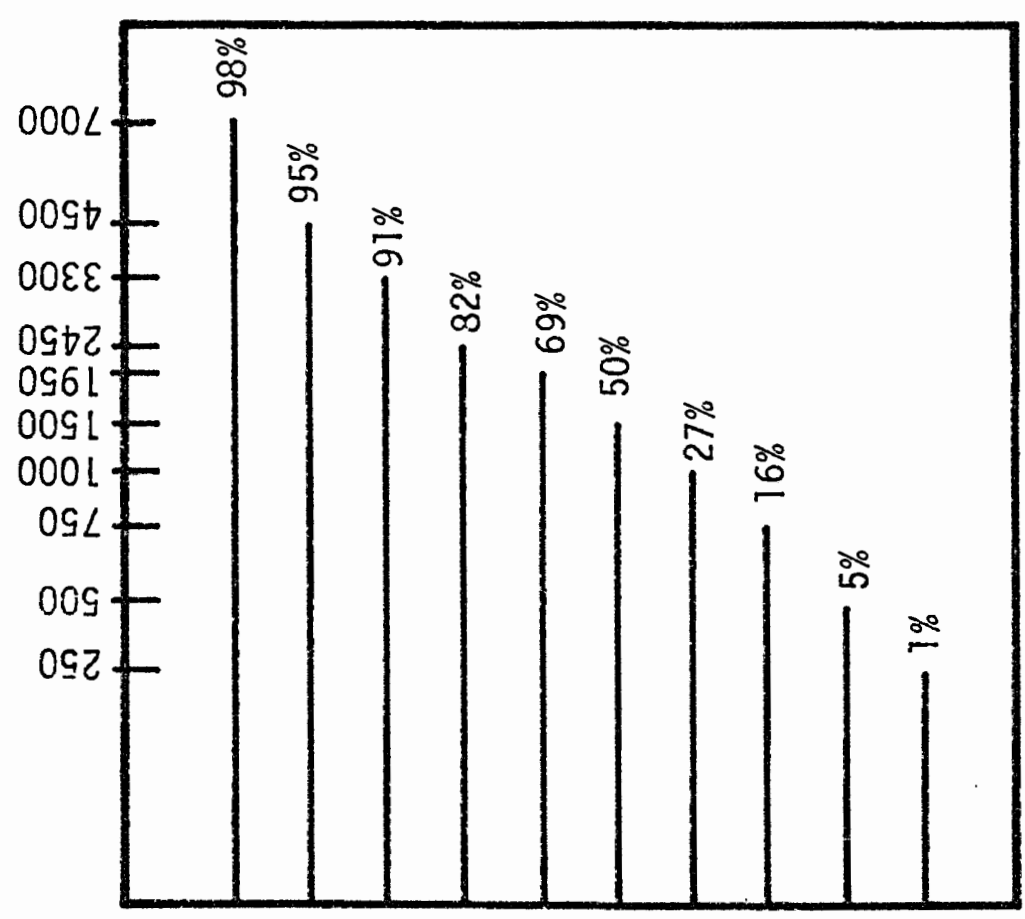

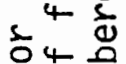

- 4.5

هئ

-

๘

$+E+$

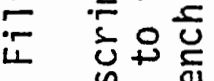

Ð

() 0

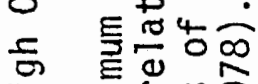

豆

n $\quad$ in

N

员

$3 \quad 0+\frac{1}{0}$

引융 잉 는욘 
speech discrimination ability of normal hearing listeners for both lowand high-pass filtered syllables. As can be seen in this figure, syllable discrimination decreases progressively as more high frequencies are el iminated. Further, these authors found that the low- and highpass articulation curves intersected at $1900 \mathrm{~Hz}$ with discrimination scores of $69 \%$ (Figure 4). Thus, it appears that at $1900 \mathrm{~Hz}$, the intelligibility for meaningless.syllables is equal when either the lower or higher frequencies are rejected.

Hirsh, et a1. (1954) compared normal hearing Tisteners' discrimination ability for meaningless syllables to different kinds of words and sentences under $10 \mathrm{~W}$ - and high-pass filtering at a $75 \mathrm{~dB}$ HL presentation leve1. As illustrated in Figure 5 , their data reveals that the articulation curves for all the different test materials appear to cross at about the same frequency, $1700 \mathrm{~Hz}$. The discrimination scores, however, become higher as the number of syllables in the test material increases. The curves indicate that discrimination ability for nonsense syllables is $75 \%$ and improves to $100 \%$ for three-syllable words at the $1700 \mathrm{~Hz}$ intersection point. These discrimination scores are slightly higher than those obtained by French and Steinberg (1947).

In a later study, wang, et al. (1978) reported a range of crossover points for high- and low-pass filtered syllable articulation curves which agreed with those obtained by both French and Steinberg (1947) and Hirsh, et a1., (1954). Using a 75dB HL intensity level, Wang, et al. noted that the point of intersection ranged from $1750-2000 \mathrm{~Hz}$ with discrimination ability varying between $75-88 \%$ correct. This suggests that variations in equipment and methodology may influence speech 


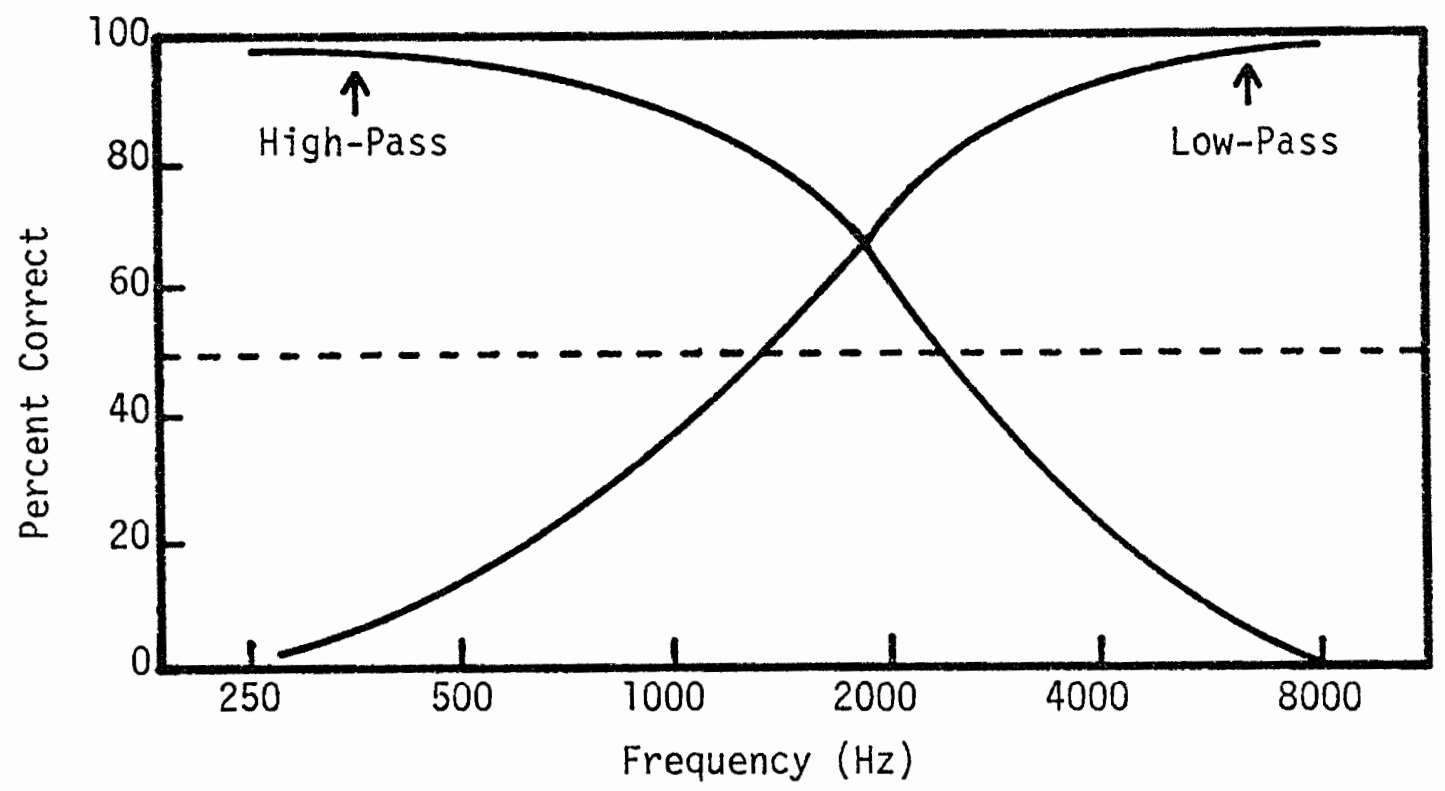

Figure 4. Effect of low-pass and high-pass filtering on the discrimination of meaningless syllables using a presentation level of 55dB HL from data obtained by French and Steinberg, 1947 (Palva, 1965). 


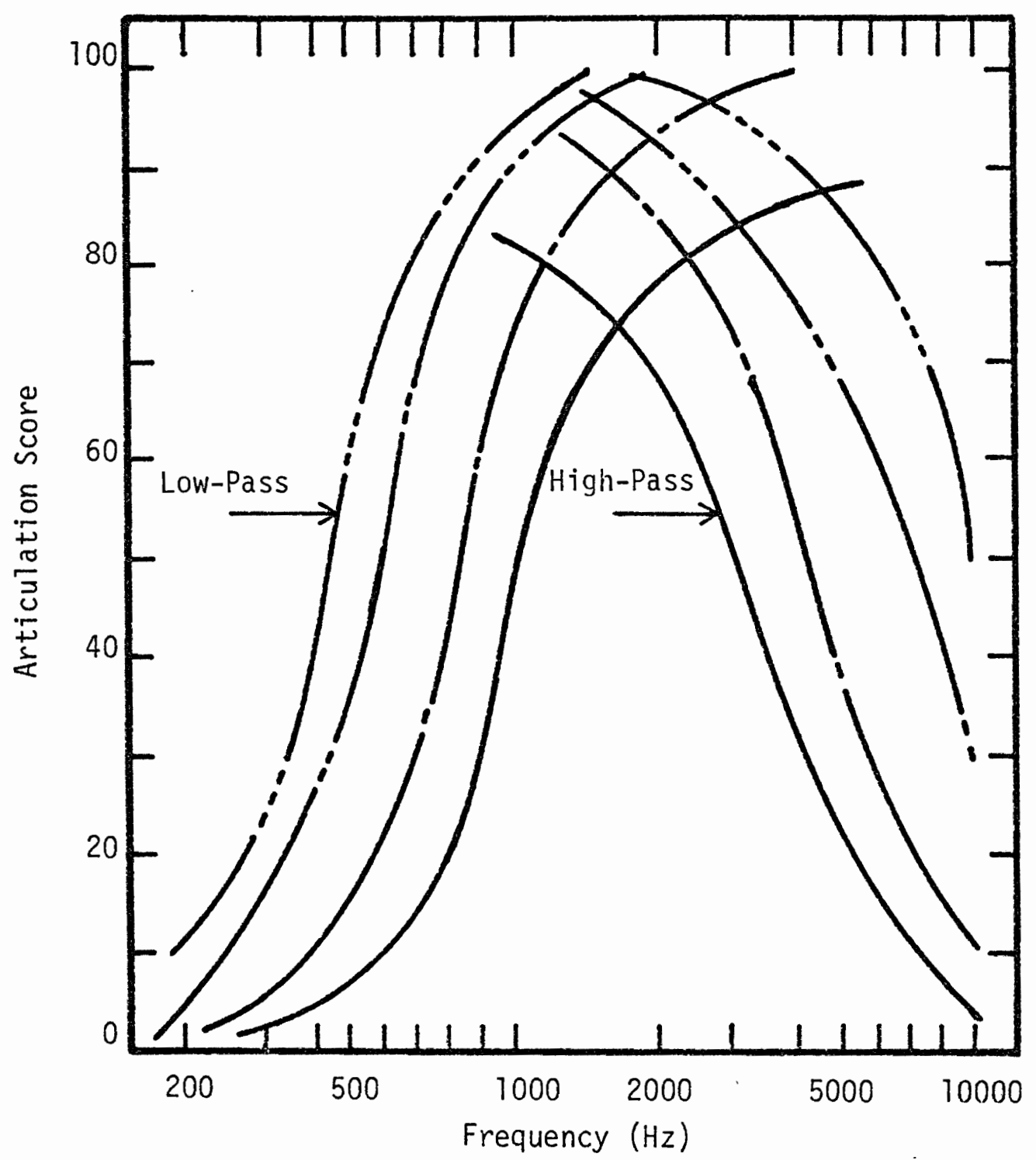

Figure 5. Idealized functions of the relations between articulation score and the cut-off frequency for low- and high-pass

filtering. The solid lines refer to nonsense syllables, while the broken lines refer to words, with the number of dashes in each break indicating the number of syllables in each word. A frequency rejection rate of $60 \mathrm{~dB} /$ octave was used (Hirsh, et al., 1954). 
discrimination ability under varying filter conditions.

Owens (1961) investigated the effects of differences in word familiarity on intelligiblity under varying conditions of low-pass filtering. Normal hearing listeners were presented monosyllabic word lists which were distorted by means of low-pass filters with cut-off frequencies of $540-3120 \mathrm{~Hz}$ and rejection rate of $30 \mathrm{~dB} /$ octave. A presentation level of $50 \mathrm{~dB}$ above the detection threshold for each specific word list was utilized. In general, it was noted that when using lowpass filtering with cut-off frequencies between $780-2040 \mathrm{~Hz}$, the difference in intelligibility between common words (39-94\%) and less common words $(9-64 \%)$ was most pronounced. When the distortion became severe, as in the $540 \mathrm{~Hz}$ low-pass condition, even familiar words were unintelligibie (24\%). Owens' observation that speech discrimination performance decreases as more of the high frequencies are filtered out is in agreement with the scores reported by both French and Steinberg (1947) and Hirsh, et al. (1954) in Table I.

Subsequent researchers have agreed that, in general, low-pass filtering causes significant decrements in speech discrimination performance as the range of speech frequencies is decreased for normal hearing 1isteners (Sanders and Goodrich, 1971; Wang, et a1., 1978; LaCroix and Harris, 1979). Furthermore, there is growing evidence that acoustic cues at or above $2000 \mathrm{~Hz}$ are necessary for understanding speech, particularly when speech is made less redundant through filtering (Kryter, 1962a and b; Liden, 1967; Sher and Owens, 1974; Chari, et a1., 1977; LaCroix and Harris, 1979; Skinner, 1980).

Narrow-band filtering of monosyllabic words seems to have 


\section{TABLE I}

COMPARISON OF DISCRIMINATION SCORES OBTAINED FROM LOW-PASS (LP)

FILTERED MEANINGLESS SYLLABLES, MONOSYLLABIC WORDS

AND BOTH FAMILIAR AND UNFAMILIAR MONOSYLLABIC

$$
\text { WORDS (After Owens, 1961). }
$$

\begin{tabular}{|c|c|c|c|}
\hline $\begin{array}{c}\text { Cut-0ff Frequency } \\
(\mathrm{Hz} \text { LP) }\end{array}$ & $\begin{array}{c}\text { Discrimination } \\
\text { Scores }\end{array}$ & $\begin{array}{c}\text { Cut-0ff Frequency } \\
(\mathrm{Hz} \text { LP) }\end{array}$ & $\begin{array}{c}\text { Discrimination } \\
\text { Scores }\end{array}$ \\
\hline \multicolumn{2}{|c|}{ French and Steinberg (1947) } & \multicolumn{2}{|c|}{ Owens (1961) - Unfamiliar Words } \\
\hline $\begin{array}{r}1950 \\
1500 \\
1000 \\
750\end{array}$ & $\begin{array}{l}70 \% \\
50 \% \\
27 \% \\
15 \%\end{array}$ & $\begin{array}{r}2040 \\
1560 \\
960 \\
780\end{array}$ & $\begin{array}{r}64 \% \\
47 \% \\
27 \% \\
9 \%\end{array}$ \\
\hline \multicolumn{2}{|c|}{ Hirsh, et al. (1954) } & \multicolumn{2}{|c|}{ Owens (1.961) - Familiar Words } \\
\hline $\begin{array}{r}2000 \\
1500 \\
1000 \\
700 \\
500\end{array}$ & $\begin{array}{l}90 \% \\
80 \% \\
63 \% \\
50 \% \\
20 \%\end{array}$ & $\begin{array}{r}2040 \\
1560 \\
960 \\
780 \\
540\end{array}$ & $\begin{array}{l}94 \% \\
85 \% \\
63 \% \\
39 \% \\
24 \%\end{array}$ \\
\hline
\end{tabular}


undergone limited research. Kryter (1960) investigated monosyllabic word intelligibility with speech filtered through several band-pass filters of varying widths having a rejection rate of $70 \mathrm{~dB} /$ octave. Table II shows the speech discrimination data obtained for several band-pass filter conditions having bandwidths of $500 \mathrm{~Hz}$ each as well as for various wider (1500-6900 Hz) band-pass filter conditions using a $55 \mathrm{~dB} \mathrm{HL}$ presentation level. It can be seen from Table II that speech discrimination ability varied as a function of the position of the center frequency for the $500 \mathrm{~Hz}$ band-pass conditions. As demonstrated by Hirsh, et al. (1954) and Wang, et al. (1978), the frequency region around 1500-1750 Hz appeared to contribute the most to speech intelligibility. Overal1, Table II shows that the filter conditions having the wider bandwidths produced the highest discrimination scores, with the widest bandpass condition $(100-7000 \mathrm{~Hz})$ producing normal discrimination performance $(95 \%)$. While the remaining three wide band-pass conditions contained the same number of frequencies $(1500 \mathrm{~Hz})$, discrimination performance decreased as the upper and lower cut-off frequencies increased.

In a study of the effects of narrow-band filtering on normal hearing listeners' monosyllabic word discrimination, Castle (1964) employed filters having center frequencies of 1080,1560 and $1920 \mathrm{~Hz}$ and rejection rates of $\geqslant 30 \mathrm{~dB} /$ octave. Normal speech discrimination performance (97-99\%) was obtained when a bandwidth of $240 \mathrm{~Hz}$ centered at 1560 and $1920 \mathrm{~Hz}$ and a bandwidth of $480 \mathrm{~Hz}$ centered at $1080 \mathrm{~Hz}$ were employed using a single filter. However, Castle reported that when connecting more than one filter in series to achieve a greater frequency rejection rate, poorer performance resulted (approximately 52-78\%) for the 240 and 
TABLE II

A COMPARISON OF THE MEAN PERCENT CORRECT SCORES FOR MONOSYLLABIC WORDS

FILTERED THROUGH VARIOUS BANDPASS SYSTEMS HAVING A REJECTION RATE OF 70dB/OCTAVE (After Kryter, 1960).

Center Frequency of $500 \mathrm{~Hz}$ Band-Pass Filter
Mean Percentage of Words Correct

$\begin{array}{ll}250 \mathrm{~Hz} & 13.00 \\ 750 \mathrm{~Hz} & 32.00 \\ 1000 \mathrm{~Hz} & 27.00 \\ 1250 \mathrm{~Hz} & 31.00 \\ 1500 \mathrm{~Hz} & 37.00 \\ 1750 \mathrm{~Hz} & 36.00 \\ 2000 \mathrm{~Hz} & 20.00\end{array}$

Upper and Lower Cut-0ff

Frequencies for Band-Pass

Filter

Mean Percentage of

Words Correct

$\begin{array}{ll}100-7000 \mathrm{~Hz} & 95.00 \\ 100-1600 \mathrm{~Hz} & 65.00 \\ 500-2000 \mathrm{~Hz} & 62.00 \\ 1000-2500 \mathrm{~Hz} & 53.00\end{array}$


$480 \mathrm{~Hz}$ band-pass conditions, regardless of the center frequency used. Normal hearing listeners' perception of one-third octave band' filtered speech was investigated by Chari, et al. (1977). These researchers filtered both meaningless syllables and monosyllabic words through one-third octave bands centered at 500, 1000, 2000, 3150 and $4000 \mathrm{~Hz}$ at a rejection rate of $50 \mathrm{~dB} /$ octave. They reported no significant difference between syllable and word intelligibility and obtained maximum discrimination performance $(50 \%)$ at the frequency band centered at $2000 \mathrm{~Hz}$ using a presentation level of $65 \mathrm{~dB} \mathrm{HL}$. A comparison of the data obtained by these authors with data from the studies by Kryter (1960) and Castle (1964) may be seen in Figure 6. Chari, et al. noted that the peak in intelligibility at the one-third octave band centered at $2000 \mathrm{~Hz}$ was in agreement with Castie's data, as well as the scores reported by French and Steinberg (1947). Kryter, on the other hand, obtained reduced discrimination scores for the band centered at $2000 \mathrm{~Hz}$. It was noted that the differences in scores between the data obtained by Chari, et al. and the scores reported by Kryter might have been due to the fact that Chari, et al. used fewer vowels in their word stimuli compared to Kryter,

Liden (1964) measured normal listeners' speech intelligibility for narrow-band filtered words at several intensity levels. Using a low frequency band-pass filter $(560-715 \mathrm{~Hz})$ with center frequency of $640 \mathrm{~Hz}$, Liden found discrimination scores to be on 7 y $7-14 \%$ at low intensity levels $(30-40 \mathrm{~dB} H \mathrm{H})$. However, speech discrimination ability rose to 30 $46 \%$ with increasing intensity $(50-60 \mathrm{~dB} \mathrm{HL})$. The intelligibility of speech through a high frequency band-pass filter $(1800-2200 \mathrm{~Hz})$ with center 
O- Castle (1964) $480 \mathrm{~Hz} \mathrm{B.W.}$

Castle (1964) $240 \mathrm{~Hz} \mathrm{B.H.}$

$\square$ Kryter (1960) $500 \mathrm{~Hz}$ B.W.

$\longrightarrow$ Chari, et al. (1977) 1/3 Octave B.W.

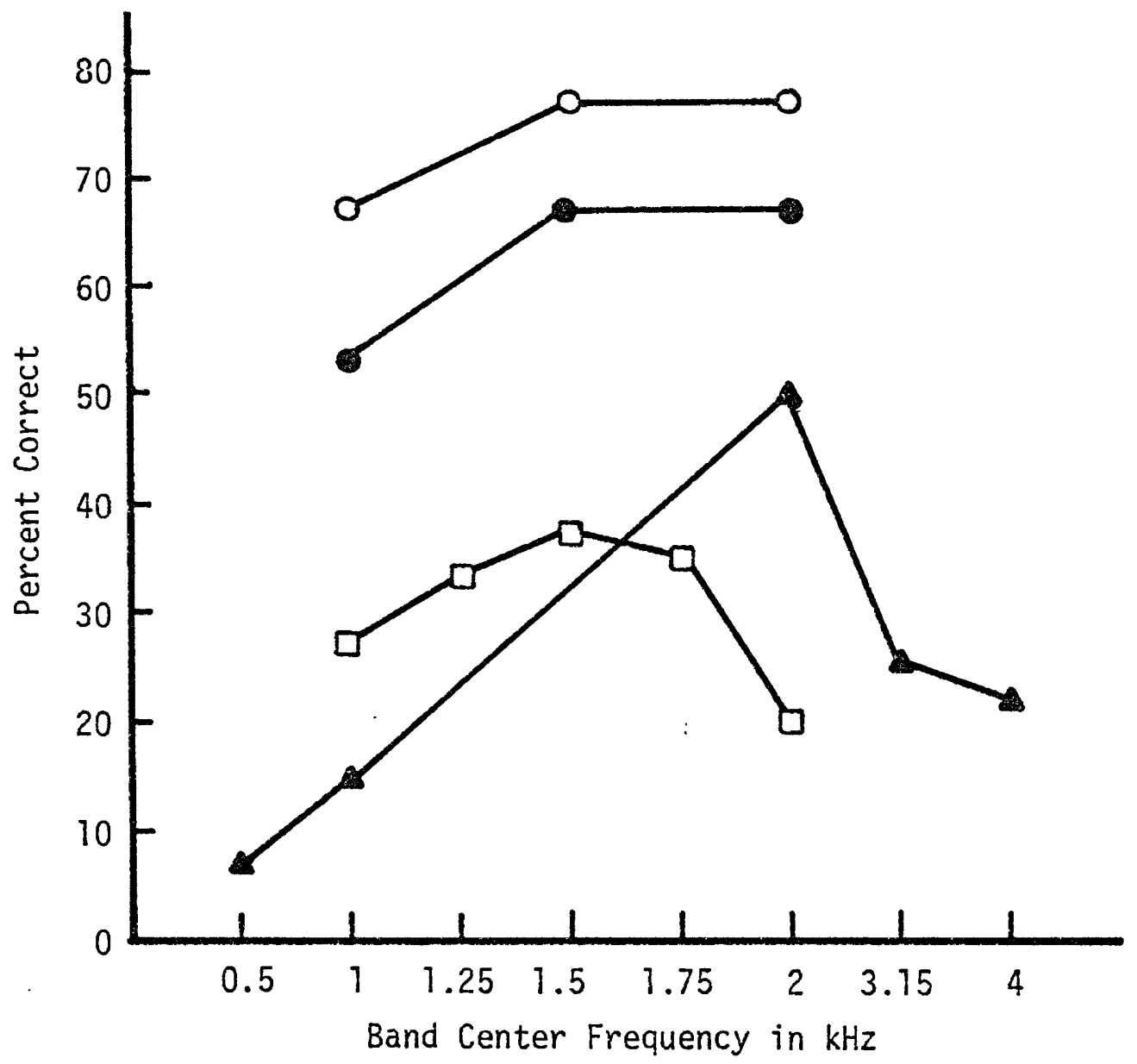

Figure 6. A comparative representation of intelligibility scores obtained utilizing narrow-band filtering (After Chari, et al., 1977). 
frequency of $2000 \mathrm{~Hz}$ also revealed a steady increase in discrimination scores with rising intensity. Liden reported a wide range of speech discrimination scores as a function of intensity for the low frequency band-pass condition ( $7-46 \%)$, while comparatively little overall variation in performance was noted in the high frequency band-pass condition $(4-21 \%)$. It is interesting to note that the scores obtained for the $60 \mathrm{~dB} \mathrm{HL}$ intensity level using the $2000 \mathrm{~Hz}$ band-pass filter (22\%) were similar to those reported by Kryter (1960), who used a presentation level of $55 \mathrm{~dB} \mathrm{HL}$.

In a much earlier study, Pollack (1948) observed that at high intensity levels, speech intelligibility was better when frequencies below $350 \mathrm{~Hz}$ were omitted. Pollack explained that at weak intensity levels, low frequencies add to the overall power of the words thereby making speech audible, whereas at high intensities, the strong low frequencies mask the weaker high frequency sounds.

A classic study by Bocca, et al. (1954) was possibly the earliest investigation utilizing filtered speech to identify the presence of a central auditory disorder. These investigators used low-pass filtered disyllabic words with a cut-off frequency of $800 \mathrm{~Hz}$. Results consistent with a follow-up study (Bocca, et al., 1955) demonstrated that normal subjects revealed similar scores of approximately $60-80 \%$ for each ear. However, patients with confirmed temporal lobe lesions demonstrated a substantial reduction in discrimination ability in the ear contralateral to the lesion in comparison to the normal subjects (Figure 7). Subsequently, other investigators have also reported considerably lower discrimination scores (by approximately $12-20 \%$ ) in the ear opposite the 


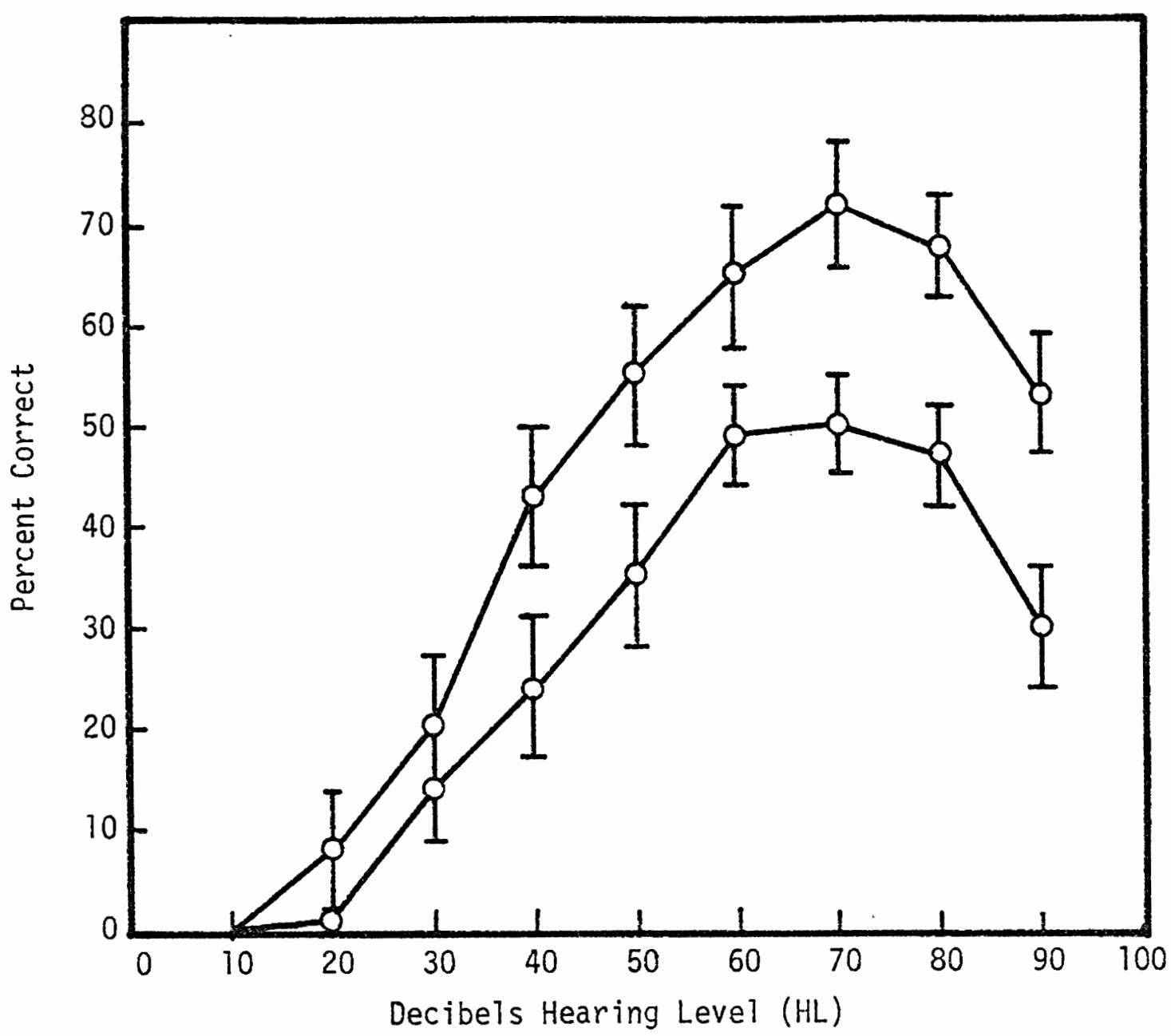

Figure 7. Average discrimination scores for filtered voice (words or short sentences) in the homolateral ear (upper curve) and contralateral ear (lower curve) for persons with temporal lobe lesions, taken from data obtained by Bocca, et al., 1954. Vertical lines indicate statistical variability (Bocca and Calearo, 1963). 
affected side when presenting monaural low-pass filtered speech to patients manifesting central auditory lesions (Jerger, 1960 and 1964; Bocca, 1967; Hodgson, 1967). Further, Liden (1964) observed similar results when using two different band-pass filtered conditions (560$715 \mathrm{~Hz}$ and $1800-2200 \mathrm{~Hz}$ ).

Welsh, et a1. (1969) investigated the effects of aging on the perception of filtered speech. A high-pass filter with a $2160 \mathrm{~Hz}$ cut-off frequency and a low-pass filter with a cut-off frequency of $540 \mathrm{~Hz}$, both having a rejection rate of $60 \mathrm{~dB} /$ octave, were utilized to create distortion in monosyliabic words. At a presentation level of $70 \mathrm{~dB}$ above the threshold for unfiltered speech, the scores for young normal hearing listeners $(30.9 \%)$ were slightly better than those for elderly normal hearing subjects $(27.4 \%)$ in the high-pass filtered condition. This difference, however, was not statistically significant. Both groups' discrimination scores were poorer for the low-pass filtered condition than for the high-pass condition, however, the performance for the younger subjects $(24.3 \%)$ was significantiy better than that of the aged subjects (11.8\%). Previously, Kirikae, et a1. (1964) also found a significant reduction in discrimination ability (by approximately 15\%) in aged listeners than for younger subjects when presenting low-pass filtered words at a cut-off frequency of $1200 \mathrm{~Hz}$ and sensation levels of $40-80 \mathrm{~dB}$.

Aging listeners have even been reported to demonstrate reduced speech discrimination utilizing unfiltered speech materials (Willeford, 1971). This reduction in speech discrimination performance has been attributed to the normal neural degeneration known to occur throughout 
the auditory system with the aging process (Schuknecht, 1974; Gang, 1976; Jerger and Jerger, 1976). Thus, this loss of intrinsic redundancy associated with aging creates a compounding effect when combined with the loss of extrinsic redundancy through acoustic filtering.

The wide variations in filtered speech discrimination scores reported throughout the literature may well be attributed to the age differences in experimental populations, differing intensity levels, as well as variations in filter cut-off frequencies and rejection rates employed by individual researchers. In general, speech discrimination ability has been reported to decrease progressively as more high frequencies are el iminated from the speech spectrum through acoustic filtering (Owens, 1961; Wang, et a1., 1978; LaCroix and Harris, 1979). In fact, acoustic information at or above $2000 \mathrm{~Hz}$ appears to be necessary for speech intelligibility (Liden, 1967; Sher and Owens, 1974; LaCroix and Harris, 1979; Skinner, 1980). When speech is distorted through narrow-band filtering, the speech discrimination performance by normal hearing listeners is significantly reduced (Kryter, 1960; Chari, et al., 1977). These low performance scores by normal 1 isteners often preclude meaningful comparisons with scores obtained from hearing impaired individuals. While gross comparisons have been made between the speech discrimination performance of normal hearing persons and individuals with retrocochlear disorders, no standard method for identifying various retrocochlear pathologies has been proposed. As a result, filtered speech testshave not been widely accepted among clinical audiologists. Consequently, researchers have focused on other means, such as intensity distortion, in an effort to develop predictive tests for 
persons with suspected retrocochlear lesions.

\section{Intensity Distortion}

Another method of experimentally degrading speech that has shown promise in determining neural lesions is loudness degradation (Palva, 1965; Lundborg, et al., 1975). With loudness degradation, the physical intensity of the signal is increased to a point where external redundancy becomes reduced. Further increases in intensity will continue to reduce the external redundancy of the speech stimuli. Persons manifesting lesions of the central auditory pathways are much more sensitive to breakdowns in the external redundancy of speech resulting from increases in intensity. This breakdown is evidenced by a reduction in speech discrimination ability at even moderately high (80-90dB $\mathrm{HL}$ ) intensity levels (Jerger, et a1., 1966; Jerger and Jerger, 1971).

A procedure for the measurement of speech discrimination ability as a function of increased intensity has been described by Jerger and Jerger (1967 and 1968). Speech stimuli consisted of lists of 50 monosyllabic words of high familiarity, containing an equal representation of a11 the phonemes (speech sounds) of the English Tanguage. These 50-word lists were presented in 5-20dB increments starting at an intensity level as low as $\mathrm{OdB} \mathrm{HL}$ and extending to $100 \mathrm{~dB} \mathrm{HL}$. This performanceintensity (PI) function test procedure has since undergone slight modifications. For instance, Jerger and Jerger (1971) presented half-lists (25 words) in 10-20dB increments starting from that intensity level yielding a discrimination score of approximately $20 \%$ and continuing to a maximum intensity level of $90 \mathrm{~dB} \mathrm{HL}$. Other investigators have utilized intensity increments as small as $4-6 \mathrm{~dB}$ and varying intensity ranges 
(Schu1tz and Streepy, 1967; Gang, 1976; Dirks, et a1., 1977). Additionally, investigators have employed different lists of monosyllabic words in their PI test procedures, however, all the lists have been reported to contain phonetically balanced (PB) words.

Performance-intensity function (PIPB) testing has proven to be a valuable tool in the differentiation of cochlear (periphera1) and retrocochlear (central) disorders (Jerger, et a1., 1966; Jerger and Jerger, 1967, 1971, 1974a and 1975; Dirks, et a1., 1977; Jerger and Hayes, 1977). That is, after reaching a maximum speech discrimination score ( $P B \max$ ), further increases in the intensity of the speech stimuli produce a marked reduction ("rollover") in speech discrimination ability. In the normal ear, increases in the loudness of speech do not impair performance on speech discrimination tasks (Jerger and Jerger, 1967; Schultz and Streepy, 1967; Dirks, et a1., 1977). However, individuals with cochlear hearing losses may exhibit mild rollover (Jerger and Jerger, 1967, 1971 and 1974a; Dirks, et a1., 1977), or in some instances, even significant rollover, comparable to that of persons with retrocochlear disorders (Dirks, et al, 1977). A comparison of performance-intensity (PIPB) test scores for persons with normal hearing, cochlear hearing loss and retrocochlear impairment may be seen in Figure 8.

Jerger and Jerger (1971) compared the performance-intensity functions (PIPB) of subjects with cochlear and retrocochlear disorders. In general, their results revealed little or no rollover (approximately 0-30\%) in cochlear disorders, pronounced rollover (approximately 30-68\%) in a11 eighth nerve disorders and varied degrees of rollover (0-65\%) in temporal lobe and brainstem disorders in the ear contralateral to the 


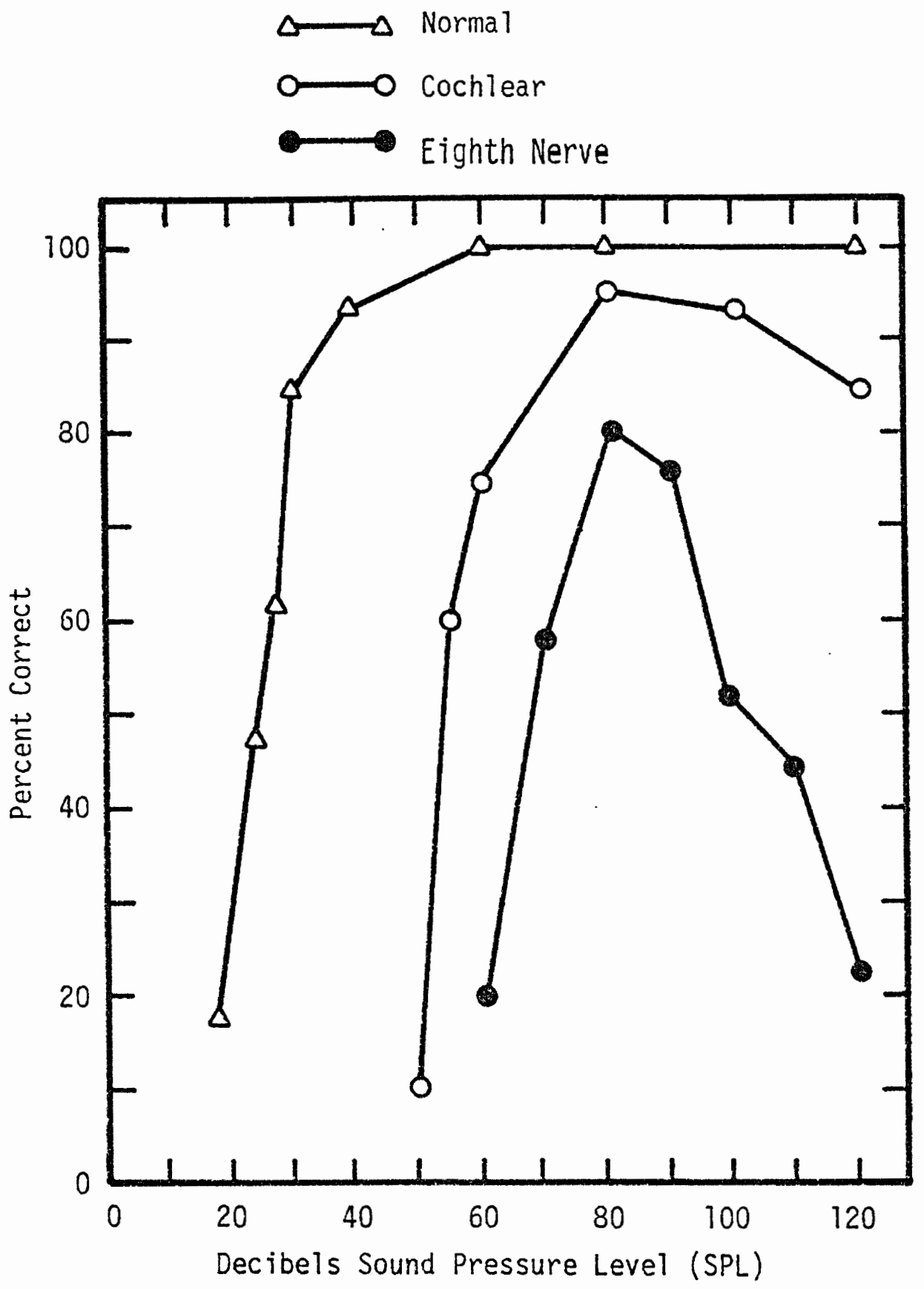

Figure 8. Performance-intensity (PI) functions for PB-50 word Tists for persons with normal hearing, cochlear hearing loss and eighth nerve damage (Jerger and Jerger, 1976). 
affected side. According to these investigators, approximately $70-80 \%$ of eighth nerve disorders will demonstrate significant rollover.

In an investigation of 16 patients with brainstem lesions, rollover of 24-64\% was observed by Jerger and Jerger (1974b). Subsequently, Jerger and Jerger (1975) compared PIPB scores for cochlear versus retrocochlear disorders and proposed that a reduction in discrimination ability in excess of $30 \%$ from the maximum discrimination score (PB $\max$ ) for standardized word lists suggests a neural site of lesion. For example, a person who obtained an $85 \%$ discrimination score at $65 \mathrm{~dB}$ HL would be diagnosed as having a neural lesion if his speech discrimination fell below $55 \%$ at any subsequent presentation level above $65 \mathrm{~dB}$ HL. Thus, the amount of rollover was determined by subtracting the lowest speech discrimination score obtained at an intensity above the optimum speech discrimination performance ( $P B$ min) from the $P B \max$ score.

Another method of quantifying the magnitude of the rollover phenomenon was proposed by Jerger and Jerger (1971). They constructed a formula in which each rollover score ( $P B \max -P B \min$ ) was divided by the $P B$ max performance. The resulting rollover index eliminated the biasing effect of differing $P B \max$ scores in determining rollover and created a sharper delineation between rollover effects of cochlear and eighth nerve hearing losses. Indices of 0.40 or less indicated a cochlear site of lesion, whereas the lowest eighth nerve index was found to be 0.45 . This formula, however, did not appear to el iminate the overlap in scores between these two groups and brainstem pathologies.

While the experimental use of performance-intensity function (PIPB) testing has proven to be a valuable tool in the isolation of advanced 
retrocochlear pathologies, several limitations have been noted in its clinical application. The most obvious limitation lies in PIPB test administration. Of critical importance to the estimation of PB max is the selection of an appropriate presentation level. It is evident that to plot an entire articulation curve for each patient would be extremely time-consuming for regular clinical purposes. While several investigators have recommended a single intensity level for establishing high word intelligibility for most patients, the lack of agreement concerning a specific intensity level has left clinicians with no standard method for measuring PB $\max$ (Carhart, 1965; Schuitz and Streepy, 1967; Tillman and 01sen, 1973; Geffner and Donovan, 1974). Furthermore, when encountering a variety of clinical patients, the determination of PB max for all or even the majority of cases at any one presentation level could lead to underestimation of PB max (Jerger and Jerger, 1974a; Dirks, et al., 1977; Orchik, et al., 1979).

Additional considerations regarding PIPB testing have arisen from investigation of the PB words themselves. Carhart (1965) compared speech discrimination scores as a function of intensity for normal hearing listeners for two different voice recordings of the same PB word lists. It was noted that the intensity level required to produce $P B \max$ performance for the two recordings differed by $15 \mathrm{~dB}$. Thus, it appears that such variables as the characteristics of the speaker's voice and quality of the recordings may influence speech discrimination performance and alter the PIPB function (Carhart, 1965; Dirks, et a1., 1977; Orchik, et a1., 1979). Further, with the use of different PB word lists among clinics, it has been suggested that both the PB max score 
and the slope of the rollover function may vary (Dirks, et al., 1977). Audiometric configuration and degree of hearing loss have also been reported to play a significant role in PB word intelligibility (Liden, 1967; Geffner and Donovan, 1974; Bilger and Wang, 1976; Jerger and Jerger, 1976b). Investigating the role of varying audiometric configurations, Geffner and Donovan (1974) reported that subjects with severe high frequency hearing losses demonstrated depressed performance scores. Similarly, Liden (1967) demonstrated that speech discrimination becomes progressively worse as the extent of high frequency hearing loss increases beyond $2000 \mathrm{~Hz}$. Thus, there appears to be a dependence of PB word discrimination on high frequency hearing sensitivity.

It has found that the frequency of occurrence and the magnitude of rollover are greater in an aged population than in a general clinic popUlation (Jerger and Jerger, 1971; Gang, 1976; Shirinian and Arnst, 1980). Some researchers reason that abnormal rollover in the aged supports the diagnostic significance of the rollover phenomenon. That is, since diagnostic auditory tests identify the site of lesion, elderly patients may show substantial rollover due to the partial eighth nerve degeneration associated with aging (Jerger and Jerger, 1976a; Dirks, et a1., 1977). Gang (1976), however, reported that elderly subjects manifesting substantial rollover in speech discrimination ability failed to demonstrate positive findings on other diagnostic tests for eighth nerve degeneration. Hence, Gang concluded that the substantial rollover effects observed among aged listeners constituted a significant limitation in the diagnostic value of the rollover test for the elderly population. 
The predictive accuracy of the rollover index for differentiating between cochlear and retrocochlear disorders appears to be positively related to the developmental stage of the retrocochlear pathology. Jerger, et a1. (1974) observed fewer retrocochlear signs on auditory tests for patients whose acoustic tumors were detected at a very early stage than for those with larger tumors detected at more advanced stages. A subsequent investigation revealed that patients with well-developed retrocochlear tumors appear to provide an optimal condition for measuring significant rollover (Dirks, et al., 1977).

It appears that presently available narrow band-pass filtered and intensity distorted speech tests, intended to identify retrocochlear pathologies, have enjoyed only questionable predictive accuracy. Problems surrounding depressed normative data and/or considerable overlap between various pathological performances continues to plague research in this area. Since neither narrow band-pass filtered or intensity distorted speech tests alone appear to be particularly sensitive to the early detection of retrocochlear lesions, a combination method is proposed.

The present study proposes that by enhancing (augmenting) only the intensity of one-third octave band filtered portions of word stimuli, a speech signal could be sufficiently degraded in order to preclude a perfect speech discrimination score by normal hearing listeners. Such a speech discrimination task would likely be more sensitive to the subtle signs associated with retrocochlear lesions, since these lesions would be manifested by a departure from the mean performance of normal hearing listeners. 
Further, it is reasoned that by augmenting (enhancing) the intensity of one-third octave discreet frequency bands within the word stimuli, an examination of components contributing to loudness degradation may be made. It is hypothesized that the breakdown in speech discrimination ability noted in individuals with neural hearing disorders may be the result of harmonic (specific frequency) distortion created when speech is presented at very intense levels. While previous investigators have employed phonetically balanced word lists in performanceintensity function testing, the relative contribution of different speech sounds within the words to the rollover phenomenon is not well known. Since it is unknown whether the suggested distortion component is high frequency (consonant) or low frequency (vowel) in nature, each possibility should be examined.

Recently, Maurer, et al. (1981) employed one-third octave bandpass augmentation to monosyllabic word lists in an effort to examine the effects of frequency-specific auditory augmentation. These authors observed large standard deviations in the performance of normal hearing listeners under low band-pass $(500 \mathrm{~Hz})$ augmentation. While decidedly smaller standard deviations were noted in the high frequency band-pass $(3150 \mathrm{~Hz})$ augmented listening condition, there was no significant re1ationship between the intensity of the augmentation and speech discrimination ability. Further, these authors observed a significant order effect, causing discrimination scores to improve as a function of the presentation order of augmented material. These authors concluded that more research was needed in order to overcome the artifact of order and to define the optimal presentation intensity level for augmented 
speech discrimination testing.

Since there is no historic precedence for this type of augmented speech discrimination test in the reported literature, it is necessary to establish normative data as a first step toward standardization of this test. Once such norms are well defined, it will be possible to make diagnostic inferences when persons with suspected retrocochlear lesions perform poorly on augmented discrimination tasks.

\section{PURPOSE}

The purpose of this study was to investigate the speech discrimination ability of normal hearing listeners in response to speech stimuli which have been separately augmented at two selected one-third octave filter bands and presented at varying intensity levels.

The question was three-fold:

1) What effect does a $500 \mathrm{~Hz}$ one-third octave band augmentation have on speech discrimination ability for normal hearing listeners?

2) What effect does a $3150 \mathrm{~Hz}$ one-third octave band augmentation have on speech discrimination ability for normal hearing listeners?

3) How is the speech discrimination ability of normal hearing listeners affected by variation in intensity presentation levels of a one-third octave band augmentation centered at $500 \mathrm{~Hz}$ compared to a one-third octave band augmentation centered at $3150 \mathrm{~Hz}$ ? 


\title{
CHAPTER III
}

\author{
METHODS
}

\section{Subjects}

Thirty-six normal hearing subjects between the ages of 19-29 years were selected from the student population at Portland State University. No subject was used in this study who reported a familial history of deafness, positive record of ear disease or manifested any abnormal auditory processing difficulty. All subjects utilized in this study had normal hearing as measured by standard air conducted pure tone and speech testing procedures. Each subject had an auditory sensitivity within $15 \mathrm{~dB}$ of audiometric zero (ANSI, 1969) for the test ear at octave test frequencies of 0.25 through $8.0 \mathrm{kHz}$ and an interaural difference no greater than $15 \mathrm{~dB}$ HL at any test frequency. Further, the speech reception threshold by air conduction was within 10dB HL of the average pure tone threshold for each ear. Strict attention was given to good speech discrimination ability ( $90 \%$ or better) in both the test and nontest ears.

\section{Procedure}

A11 potential subjects were given an audiological assessment utilizing standard clinical procedures. Each subject was queried regarding any familial history of deafness or positive record of ear disease prior to any testing to confirm his or her eligibility for this investigation. Only one ear per subject was used for the experimental test conditions. The selection of a right or left test ear was determined randomly by 
flipping a coin to determine whether the right or left ear would be used for subject \#1; thereafter, the ear used followed an alternate pattern. Thus, an equal number of right and left ears was used. Each of the subjects was assigned an individual number to maintain anonymity for al1 experimental data collected.

The subjects wore earphones while seated in a double-walled suite and instructed to write down each recorded word exactly as they heard it. In the event that a subject was uncertain of a word, he or she was encouraged to guess. Subjects were provided with answer sheets for their written responses. To prevent the possible intervening effects of a temporary threshold shift, a minimum two minute rest period was given between each test condition. The written responses constituted the raw data by which total percentage correct responses were determined for each experimental condition.

In order to insure that the experimental data reflected only the test ear responses, contralateral masking was employed during al1 listening conditions. Wide band masking noise, which has a spectral composition similar to speech, was presented to the nontest ear at a level $20 \mathrm{~dB}$ below the test ear stimuli.

Speech discrimination test materials consisted of recorded monosyllabic word lists (Campbe11, 1965). Each subject was presented three 50-word 1ists, one was augmented at a one-third octave band-pass with center frequency of $500 \mathrm{~Hz}$, another was augmented at a one-third octave band-pass with center frequency of $3150 \mathrm{~Hz}$ and a third was augmented unfiltered. Under each one-third octave band pass listening condition, the left channel output (unfiltered word) was set at a sensation. 
level of $45 \mathrm{~dB}$ above each subject's speech reception threshold, while the output from the right channel (the augmented only portion of the word) was delivered at a level between $5-55 \mathrm{~dB}$ above the level of the unfiltered word in the left channel. The sensation level of the augmented version of the words was selected using the following criteria: 1) the sensation level could not be louder than $5 \mathrm{~dB}$ below a subject's uncomfortable listening level, 2) only sensation levels of $5,15,25,35,45$ or $55 \mathrm{~dB}$ above the unfiltered word level were selected and 3) exactly six subjects were presented with test material at each sensation level so that if one level had reached quota, a lower level was chosen. These criteria assured an equal number of experimental conditions at each sensation level.

These two intensity disparate signals were fed to the same ear by delivering the output from the right and left channels simultaneously into one earphone. The third word list (augmented unfiltered) served as the control and was delivered through both channels at the same sensation levels as the filtered augmented words in the other two experimental conditions. All testing and data were expressed in the numerical value of the intensity dials even though mixing right and left channels produced slightly less (approximately 10dB) sound pressure level (SPL) output.

The intensity disparity levels for this investigation were selected after reviewing the findings of a previous augmented speech study utilizing a sample of 28 normal hearing listeners (Maurer, et al., 1981). It was found that a sensation level of $45 \mathrm{~dB}$ re speech reception threshold was most often chosen as a comfortable listening level for 
unfiltered, unaugmented speech. Further, a wide range of scores and standard deviations were obtained utilizing augmentation at disparity levels of $25-55 \mathrm{~dB}$ above the unfiltered word level. Therefore, it seemed propitious to examine the intelligibility function created when the augmented portion of the words was presented: 1) at an intensity level slightly above $(5 \mathrm{~dB})$ the level of the unfiltered words, 2) at a level widely disparate with the unfiltered words and 3) at several intensity increments between these two extremes. Since a possible. "rollover" in discrimination ability with increased intensity was suspected, sensation levels between $5-55 \mathrm{~dB}$ above the unfiltered word level were delivered at 10dB increments. In addition, it was reasoned that by examining the resulting articulation function, an optimum sensation level for augmented speech discrimination testing for normal hearing listeners might be obtained.

The presentation order of the three experimental conditions (two filtered augmentations and one unfiltered augmentation) was predetermined such that each experimental condition was presented an equal number of times in all three positions for each listening level. The order of presentation was determined in a random fashion by rolling a die.

In order to avoid the practice effects created by the adaptation to a novel listening task, the adaptation to loud suprathreshold stimuli and the adjustment to a written response mode, five practice words preceded each 50-word list. Each of the three 50-word 1ists were preceded by a different set of practice items which were augmented according to the experimental condition they preceded. In addition, each practice word was followed by its unaugmented version in order to provide the 
subject with immediate feedback. Further, a brief set of recorded instructions was included before each experimental condition.

\section{$\underline{\text { Instrumentation }}$}

A stimulus tape was recorded on a stereo cassette recorder. The speech stimuli consisted of two 25 monosyllabic word lists (lists $N$ and P; Campbe11, 1965), which exhibit high "parallel forms" reliability with respect to discrimination difficulty (Adam, 1978). In addition, these two word lists have demonstrated a high interlist correlation with respect to phonemic content and word familiarity (Campbe11, 1965). That is, a listener should obtain the same speech discrimination score with either list, regardiess of the presentation mode.

In order to avoid the learning effect created by a serial presentation of the same word list for three experimental conditions, the two 25-word 1 ists were combined and the 50 words were randomly ordered three times by means of a table of random numbers (Freund, 1973). The three randomly ordered 50 -word lists were spoken by a male with a general American dialect through the microphones of a dual channel audiometer (Maico, Model MA 24B). The output from the right channel to the audiometer was fed through a one-third octave filter (Bruel and Kjaer, Model 1616) with a rejection rate of $50 \mathrm{~dB} /$ octave, where only the selected frequency band was fed to the right channel of a stereo cassette recorder (Hitachi, Model D 90-S). The output from the left channel of the audiometer was fed through directly to the left channel of the cassette recorder without filtering. See Figure 9. Thus, the stereo cassette tape contained an unfiltered version of each word on the left channel, coincident with the one-third octave spectral information recorded on 


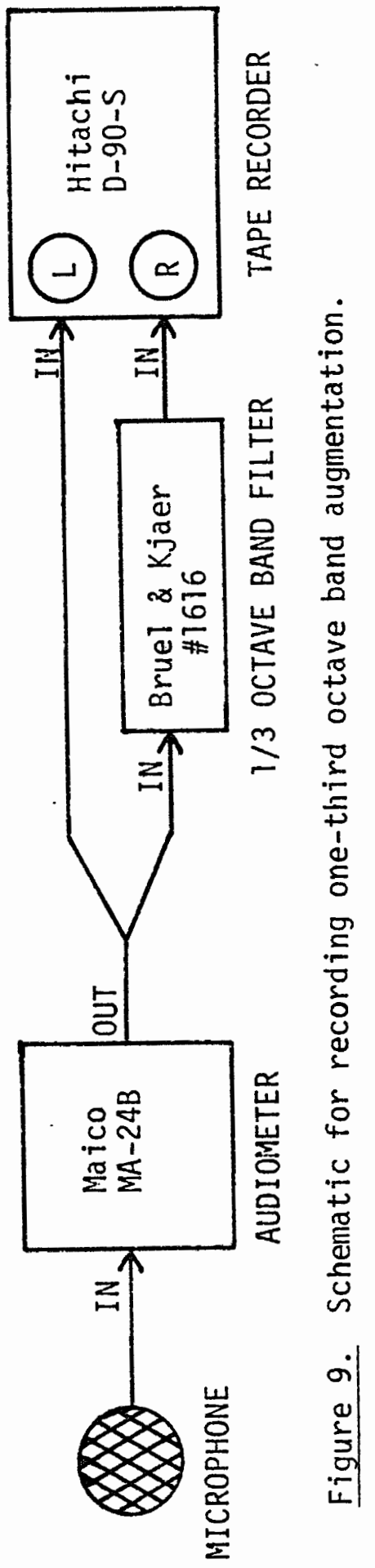


the right channel. This master tape recording was made utilizing a high bias $(70 \mu \mathrm{sec})$, low noise metal tape (Maxel1, MX C-60). For each of the augmented test conditions, the right and left channels were always delivered to the same ear simultaneously, resulting in an augmented presentation.

This two channel recording technique allowed independent manipulation of the intensity relationship between the word and its one-third octave augmentation component. For the unfiltered augmented test condition, the stimulus words were recorded through the audiometer directly onto both channels of the stereo cassette tape recorder, bypassing the one-third octave filter. Right and left channels containing this unfiltered augmented word list were also delivered simultaneously to the same ear.

The three experimental conditions were rerecorded six times by means of a second cassette recorder (Technics, Model RS-263AUS) and a low noise, high bias tape (Maxell, UDXL II C-90). This allowed all possible combinations of presentation order for each experimental condition.

The stereo cassette tape output (Technics, Model RS-263AUS) was jacked into a dual channel audiometer (Maico, Model MA 25B) such that the right channel controlled the output from the right channel of the cassette recorder and the left channel controlled the output from the left channel of the cassette recorder. The output from the audiometer was patched through a double-walled acoustic suite (Industrial Acoustics Company, Model 1403) to the test ear via a single earphone from a pair of standard audiometric headphones (Telephonics, Model TDH 39) mounted 
in foam rubber cushions (Acoustic Research, Model MX 41). The second earphone delivered wide band masking noise from a masking generator (Beltone, Model NB 102) to the nontest ear.

\section{Calibration}

The output at the earphones for both right and left channels of the audiometer was electro-acoustically calibrated prior to each experimental testing session to reflect the current ANSI (1969) standards using a precision sound level meter (Bruel and Kjaer, Model 2203) and an artificial ear (Bruel and Kjaer, Model 4152). A prerecorded segment of speech spectrum calibration noise was utilized to calibrate the speech circuit. In addition, a speech spectrum calibration signal preceded each recorded experimental condition to allow VU monitor adjustments prior to the presentation of each word 1 ist. 
CHAPTER IV

RESULTS

The purpose of this study was to investigate the effects of a $500 \mathrm{~Hz}$ and $3150 \mathrm{~Hz}$ one-third octave band augmentation on the speech discrimination ability of normal hearing listeners and whether such effects vary with signal presentation level. Data was collected and analyzed for subject responses to monosyllabic words at six signal intensity disparity levels. The augmented portion of the word was systematically varied from $5-55 \mathrm{~dB}$ above the intensity level of the unfiltered version of the word. Each subject also listened to an unfiltered augmented version of the task at a predetermined disparity level in order to provide a nonfiltered comparison score.

The raw performance data (percent correct scores) for each of the three augmented listening conditions were tabulated and analyzed using an Analysis of Variance, Two-Factor Mixed Design for Repeated Measures on One Factor (Bruning and Kintz, 1977). The results of this analys is revealed that: 1) intensity disparity level significantly affected the overal1 performance scores $(p<.001), 2)$ subjects' speech discrimination performance varied significantly as a function of type of augmentation $(p<.001)$ and 3$)$ there was a significant interaction effect between the intensity disparity level and type of augmentation on speech discrimination ability $(p<.001)$. Further analys is was performed in order to determine the nature of the interactions between augmentation and disparity 
level on speech discrimination performance.

Speech discrimination data for the $500 \mathrm{~Hz}$ augmented 1 istening condition indicated that optimum performance (96\%) was obtained when the augmented portion of the word was $5 \mathrm{~dB}$. louder than the unfiltered counterpart, or at a $5 \mathrm{~dB}$ disparity level. Table III reveals that as the disparity level increases, discrimination ability decreases (rolls-over) to a minimum of $50 \%$ at the $55 \mathrm{~dB}$ disparity level. While the percent performance differences between successively increasing disparity levels appear in several instances to be significant, the Scheffe post hoc test for differences between means indicated that only the performance difference between the $25 \mathrm{~dB}$ and $35 \mathrm{~dB}$ disparity levels was statistically significant $(p<.05)$. Statistical significance $(p<.05)$ was also found between the lowest disparity level $(5 \mathrm{~dB})$ and the disparity levels of $35 \mathrm{~dB}$ and greater. The lack of statistical significance between successively increasing disparity levels is probably best accounted for by the large standard deviations in four of the six presentation levels.

The $3150 \mathrm{~Hz}$ augmentation data indicated that the optimum performance $(97 \%)$ occurred at the $25 \mathrm{~dB}$ disparity level (Table III). A reduction in speech discrimination ability at successively smaller as well at successively larger disparity levels from the $25 \mathrm{~dB}$ level was observed. A similar variation in the standard deviations for the mean performances was also noted on both sides of the $25 \mathrm{~dB}$ disparity level, that is, standard deviations increased both above and below this disparity level. However, these differences in mean performance were not found to be statistically significant. All mean performance scores for the $3150 \mathrm{~Hz}$ augmented listening condition, with the exception of the $55 \mathrm{~dB}$ disparity 


\section{TABLE III}

A COMPARISON OF THE MEAN PERCENT CORRECT SCORES AND STANDARD DEVIATIONS FOR THE $500 \mathrm{~Hz}, 3150 \mathrm{~Hz}$ AND UNFILTERED AUGMENTED

EXPERIMENTAL CONDITIONS AT EACH OF THE

SIX DIFFERENT INTENSITY

PRESENTATION LEVELS

\begin{tabular}{|c|c|c|c|c|c|c|c|}
\hline \multirow{2}{*}{$\begin{array}{l}\text { Augmented } \\
\text { Listening } \\
\text { Condition }\end{array}$} & \multirow{2}{*}{$\begin{array}{l}\text { Percentage } \\
\text { of Words } \\
\text { Correct }\end{array}$} & \multicolumn{6}{|c|}{ *Disparity Level in $\mathrm{dB} \mathrm{HL}$} \\
\hline & & 5 & 15 & 25 & 35 & 45 & 55 \\
\hline \multirow{2}{*}{$\begin{array}{l}500 \mathrm{~Hz} \\
1 / 3 \text { octave } \\
\text { band-pass }\end{array}$} & $\bar{x}$ & 96.00 & 89.33 & 89.67 & 69.33 & 64.00 & 50.00 \\
\hline & S.D. & 2.53 & 17.50 & 4.08 & 13.49 & 19.92 & 19.72 \\
\hline $\begin{array}{l}3150 \mathrm{~Hz} \\
1 / 3 \text { octave }\end{array}$ & $\bar{x}$ & 94.67 & 96.67 & 97.00 & 96.00 & 91.00 & 88.67 \\
\hline band-pass & S.D. & 4.32 & 3.01 & 2.45 & 4.29 & 5.76 & 6.65 \\
\hline \multirow[t]{2}{*}{ Unfiltered } & $\bar{x}$ & 97.76 & 99.67 & 98.00 & 96.33 & 97.00 & 93.67 \\
\hline & S.D. & 2.34 & 0.82 & 3.10 & 4.27 & 3.29 & 1.97 \\
\hline
\end{tabular}

* For each listening condition, the words were presented at two separate intensity levels simultaneously, such that the unfiltered portion of the words was delivered at $45 \mathrm{~dB}$ above the subjects' speech reception thresholds and the augmented portion of the words was delivered at one of the experimental intensity disparity levels. 
presentation level, fell within the range of normal speech discrimination ability of $90-100 \%$ (Goetzinger, 1978).

The unfiltered augmented performance data fell within the normal limits for speech discrimination ability across all disparity levels (Table III). No systematic variation in either the mean performance scores or standard deviations was observed across the experimental disparity levels. Further, there were no statistically significant differences found between the mean performance scores at any two intensity disparity levels for this listening condition.

A comparison of the three augmented listening conditions revealed that when the disparity level between the word and its augmented portion was slight $(5 \mathrm{~dB})$, there appeared to be very little difference in discrimination ability regardless of the frequency of the augmentation. However, the $t$ test for correlated means did reveal a statistically significant difference between the unfiltered augmentation and both the $500 \mathrm{~Hz}$ and $3150 \mathrm{~Hz}$ one-third octave band augmentation scores at the $5 \mathrm{~dB}$ disparity level ( $p<.025$ and $p<.05$, respectively). With disparity levels of $35 \mathrm{~dB}$ and greater, there was a significant difference between the $500 \mathrm{~Hz}$ augmented condition and both the $3150 \mathrm{~Hz}$ and unfiltered augmented conditions. For each of the three highest disparity levels, 35,45 and $55 \mathrm{~dB}$, the $500 \mathrm{~Hz}$ augmented list produced significantly poorer discrimination performances $(p<.005)$. In addition, a statistically significant difference was found between mean performances for the $500 \mathrm{~Hz}$ and unfiltered augmented conditions at the $25 \mathrm{~dB}$ disparity level $(p<.005)$.

A statistically significant difference between discrimination scores at the $15 \mathrm{~dB}$ disparity level was revealed only when comparing the 
$3150 \mathrm{~Hz}$ and unfiltered augmented listening conditions $(p<.025)$.

Significant mean performance differences were also found at the $45 \mathrm{~dB}$ $(p<.025)$ and $55 \mathrm{~dB}(p<.05)$ disparity levers between the $3150 \mathrm{~Hz}$ and unfiltered augmentation data.

Table IV 7 ists the mean performance scores and standard deviations according to order of presentation for each augmented listening condition. Although each experimental condition was presented an equal number of times in the first, second and third positions, a systematic order effect was observed for the $3150 \mathrm{~Hz}$ augmentation. The discrimination performance for this condition varied significantly between the first and third positions $(p<.005)$ as well as between the second and third positions $(p<.05)$. No statistical significance was found in the difference between the mean performances for the first and second positions. A systematic order effect was not observed for either the $500 \mathrm{~Hz}$ or unfiltered augmented conditions. 
TABLE IV

THE MEAN PERCENT CORRECT SCORES AND STANDARD DEVIATIONS ACCORDING TO ORDER OF PRESENTATION FOR EACH OF THE THREE AUGMENTED EXPERIMENTAL CONDITIONS

\begin{tabular}{ccccc}
\hline \hline & $\begin{array}{c}\text { Percentage } \\
\text { of. Words } \\
\text { Correct }\end{array}$ & $\begin{array}{c}500 \mathrm{~Hz} \\
1 / 3 \text { Octave } \\
\text { Band-Pass }\end{array}$ & $\begin{array}{c}3150 \mathrm{~Hz} \\
\text { B } / 3 \text { Octave } \\
\text { Band-Pass }\end{array}$ & Unfition \\
\hline First & $\bar{X}$ & 71.83 & 91.33 & 96.67 \\
& S.D. & 28.24 & 4.85 & 2.99 \\
Second & $\bar{X}$ & 81.17 & 93.50 & 98.17 \\
& S.D. & 16.76 & 5.54 & 3.13 \\
Third & $\bar{X}$ & 76.17 & 97.17 & 96.33 \\
& S.D. & 18.79 & 4.13 & 3.50 \\
\hline
\end{tabular}


CHAPTER $V$

\section{DISCUSSION AND CONCLUSIONS}

The results from the present study indicate that in a population of young norma] hearing listeners, the one-third octave band augmentation of speech test material is sufficient to preclude a $100 \%$ speech discrimination performance. While the high frequency augmented condition $(3150 \mathrm{~Hz})$ produced performance scores within or near the normal range of speech discrimination ability $(90-100 \%)$, the mean data indicated that a perfect score would not be expected in a normal hearing population, regardless of intensity presentation level. On the other hand, the low frequency $(500 \mathrm{~Hz})$ augmented condition demonstrated a significant rollover in discrimination ability with increasing presentation levels. This rollover phenomenon associated with the $500 \mathrm{~Hz}$ augmented condition was statistically significant only at the $35 \mathrm{~dB}$ disparity level and above. Therefore, the diagnostic value of these presentation levels $(35,45$ and $55 \mathrm{~dB})$ is questionable, especially given the large standard deviations obtained at each of these levels.

Disregarding the $5 \mathrm{~dB}$ disparity level for the $500 \mathrm{~Hz}$ augmented condition, the $25 \mathrm{~dB}$ disparity presentation level for both the $500 \mathrm{~Hz}$ and the $3150 \mathrm{~Hz}$ augmented conditions appears to be an optimum balance between loudness distortion and the distortion created by the filtered augmentation. That is, the mean performance scores for the two filtered augmented listening conditions at the $25 \mathrm{~dB}$ level represented high 
discrimination performance while still employing a substantial amount of frequency augmentation. The desirability of the $25 \mathrm{~dB}$ disparity level is further supported by the fact that low standard deviations were observed under both filtered conditions. Therefore, a $25 \mathrm{~dB}$ intensity disparity level would seem to have the greatest utility in a clinical situation, since a small deviation from the normative data would have the greatest likelihood of indicating pathology in the listener. Additionally, this presentation level would offer greater flexibility than higher disparity levels in terms of usable presentation levels on most clinical audioneters.

The generally small standard deviations noted for the mean performance scores across all intensity disparity levels for the $3150 \mathrm{~Hz}$ augmentation data suggest that this condition may be potentially significant for diagnosing central auditory disorders. That is, the sensitivity of this augmented word list to slight variations in speech discrimination performance should enhance the identification of subtle discrimination changes associated with early developing retrocochlear lesions.

The present investigation also reveals that the highest speech discrimination performance scores were obtained in the unfiltered augmented condition. Under this condition, normal hearing listeners obtained very high (94-100\%) discrimination scores across al1 intensity presentation levels. The data suggest that this listening condition does not sufficiently tax the auditory pathways of persons with normal hearing.

Since the major variable in the unfiltered augmented condition was intensity, it could be reasoned from the present data that intensity 
alone may not be the significant parameter in the rollover phenomenon. Rather, it may be inferred that the reduced discrimination scores observed in the filtered augmented conditions were the result of the combination of frequency and intensity distortion, with frequency playing the dominant role. Further, since the $500 \mathrm{~Hz}$ augmentation produced the poorest discrimination performance across all presentation levels (except at the $5 \mathrm{~dB}$ disparity level), the low frequency distortion component appears to have a more deleterious effect on speech discrimination ability. This observation is consistent with upward spread of masking theories, where higher frequency speech components are masked by their louder low frequency counterparts (Wegel and Lane, 1924; Pollack, 1948; Bess and Townsend, 1977). While the upward spread of masking phenomenon is not new to researchers dealing with speech acoustics, an in-depth content analys is of the words incorrectly perceived under this listening condition may provide valuable insight in the future construction of low frequency augmented word discrimination lists. With a carefully constructed word list, it may be possible to produce higher performance scores with the use of significantly fewer items and therefore be more efficient in the assessment of rollover.

In summary, the one-third octave band augmented speech discrimination tests employed in this investigation appear to preclude perfect discrimination performance in normal hearing listeners, thereby enhancing the diagnostic value of rollover testing. Although a substantial reduction in discrimination performance was only observed for the low frequency $(500 \mathrm{~Hz})$ augmentation condition, this finding should ultimately lead to a more expedient method for evaluating neural degeneration 
through speech discrimination testing. The relatively small standard deviations obtained across all the intensity presentation levels for the high frequency $(3150 \mathrm{~Hz})$ augmentation condition support its potential as a diagnostic test. Further, a disparity presentation level of $25 \mathrm{~dB}$ appeared to provide an equal interaction between loudness distortion and the distortion created by filtered augmentation and was reasoned to be an optimum disparity level for presenting augmented speech discrimination material in a clinic population.

The prerecorded format and the use of standardized word 1ists make the present augmented speech test readily adaptable for most clinical protocols. However, further research is warranted before it can be broadly advocated as a viable diagnostic tool.

\section{Implications for Further Research}

Analysis of the results obtained in the present study revealed several areas of future research. Since it appears that the rollover phenomenon may be dominated by frequency distortion, a content analys is of the words missed under various augmented listening conditions would provide a clearer picture of the specific speech components contributing to the reduction in discrimination performance. Additional research should include the use of different standardized word lists under the same augmentation. Such data would allow an analys is of the test-retest reliability of augmented speech testing and possibly lead to the widespread application of this procedure in clinical settings.

The repeated measures design of the present investigation utilized a small sample of normal hearing 1 isteners $(n=6)$ for each intensity disparity level. While this design allowed measurement of intra-subject 
variation as a function of augmentation, it provided 1 imited analysis of inter-test reliability among subjects at the various intensity presentation levels for each augmented condition. Therefore, future research should include a larger sample of listeners for each disparity level.

Finally, the rationale for the present study indicated that an augmented discrimination test would reduce the extrinsic redundancy of speech and thus tax the central auditory pathways. Therefore, the clinical impact of this reduction in redundancy should be investigated utilizing a population of persons with confirmed retrocochlear lesions. 


\section{REFERENCES}

Adam, A.J., "A Correlational Analys is of the Campbell Reconstructed Half Word Lists Among an Elderly Population." Unpublished Research, Portland State University, 1978.

American National Standards Institute, Specifications for Audiometers. ANSI S3.6-1969, New York: American National Standards Institute, Inc. , 1970.

Bess, F.H. and Townsend, T.H., "Word Discrimination For Listeners With Flat Sensorineural Hearing Losses." JSHD, 42:232-7, 1977.

Bilger, R.C. and Wang, M.D., "Consonant Confusions in Patients With Sensorineural Hearing Loss." JSHR, 19:718-48, 1976.

Bocca, E., "Distorted Speech Tests." IN: Sensorineural Hearing Processes and Disorders, Graham, A.B. (Ed.), Boston: Little, Brown and Company, 1967.

Bocca, E. and Calearo, C., "Central Hearing Processes." IN: Modern Developments in Audiology, Jerger, J. (Ed.), New York: Academic Press, 1963.

Bocca, E., Calearo, C. and Cassinari, V., "A New Method for Testing Hearing in Temporal Lobe Tumors." Acta Otolarygol., 44-219, 1954.

Bocca E., Calearo, C., Cassinari, V. and Migliavacca, F., "Testing 'Cortical' Hearing in Temporal Lobe Tumors." Acta Otolaryngol., 45:289-304, 1955.

Bruning, J.L. and Kintz, B.L., Computational Handbook of Statistics. Glenview: Scott, Foresman and Company, 1977.

Campbel1, R.A., "Discrimination Test Word Difficulty." JSHR, 8:13-22, 1965.

Carhart, R., "Problems in the Measurement of Speech Discrimination." Arch. Otolaryngol., 82:253-60, 1965.

Castle, W.E., "Effects of Selective Narrow-Band Filtering on the Perception by Normal Listeners of Harvard PB-50 Word Lists." JASA, 36:1047, 1964.

Chari, N.C.A., Herman, G. and Danhauer, J.L., "Perception of One-Third Octave Band Filtered Speech." JASA, 67:576-80, 1977. 
Danhauer, J.L., Chari, N.C.A. and Herman, G., "Normal-Hearing Subjects' Perception of Speech Through One-Third Octave Bands." JAR, 17:275-81, 1977.

Dirks, D.D., Kamm, C., Bower, D. and Betsworth, A., "Use of Performance-Intensity Function For Diagnosis." JSHD, 42:408-15, 1977.

Durrant, J.D. and Lovrinic, J.H., Bases of Hearing Science. Baltimore: The Williams and Wilkins Company, 1977.

French, N.R. and Steinberg, J.C., "Factors Governing the Intelligibility of Speech Sounds." JASA, 19:90-119, 1947.

Freund, J.E., Modern Elementary Statistics. Englewood Cliffs: PrenticeHall, Inc., 1973.

Gang, R.P., "The Effects of Age on the Diagnostic Utility of the Rollover Phenomenon." JSHD, 41:63-9, 1976.

Geffner, D. and Donovan, N., "Intelligibility Function of Normal and Sensorineural Loss Subjects on the W-22 Lists." JAR, 14:82-7, 1974.

Goetzinger, C.P., "Word Discrimination Testing." IN: Handbook of Clinical Audiology, Katz, J. (Ed.), Baltimore: The Williams and Wilkins Company, 1973.

Hirsh, I.J., Reynolds, E.G. and Joseph, M., "Intelligibility of Different Speech Materials." JASA, 26:530-8, 1954.

Hodgson, W.R., "Audiological Report of a Patient with Left Hemispherectomy." JSHD, 32:39-45, 1967.

Jacobs, S.W. and Francone, C.A., Structure and Function in Man.

Philadelphia: W.B. Saunders Company, 1970.

Jerger, J., "Audiological Manifestations of Lesions in the Auditory Nervous System." Laryngoscope, 4:417-25, 1960.

, "Auditory Tests for Disorders of the Central Auditory Mechanism." IN: Neurological Aspects of Auditory and Vestibular Disorders. Fields, W.S. and Alford, B.R. (Eds.), Springfield: Charles C. Thomas, Publisher, 1964.

, "Diagnostic Audiometry." IN: Modern Developments in Audiology, Jerger, J. (Ed.), New York: Academic Press, 1973.

Jerger, J., Harford, E., Clemis, J. and Alford, B., "The Acoustic Reflex in Eighth Nerve Disorders." Arch. Otolaryngol., 99:409-13, 1974.

Jerger, J. and Hayes, D., "Diagnostic Speech Audiometry." Arch. Otolaryngol., 103:216-22, 1977. 
Jerger, J. and Jerger, S., "Audiological Comparison of Cochlear and Eighth Nerve Disorders." Ann. Otol. Phinol. Laryngol., 83:275$85,1974 a$.

, "Auditory Findings in Bra in Stem Disorders." Arch. Otolaryngol., 99:342-50, 1974b.

, "Comment on 'The Effects of Age on the Diagnostic Utility of the Rollover Phenomenon." JSHD, 41:556-7, 1976a.

, "Diagnostic Significance of PB Word Functions." Arch. Otolaryngol.,, 93:573-80, 1971.

, "Estimating Speech Threshold From PI-PB Function." Arch. Otolaryngo 1., 102:487-96, 1976b.

, "Extra and Intra-Apial Brain Stem Disorders." Audiology, 14:93-117, 1975.

, "Progression of Auditory Symptoms in a Patient With Acoustic Neurinoma." Ann. Otol. Rhinol. Laryngol., 77:230-42, 1968.

, "Psychoacoustic Comparison of Cochlear and VIII Nerve Disorders." JSHR, 10, 659-88, 1967.

Jerger, J., Jerger, S., Ainsworth, J. and Caram P., "Recovery of Auditory Function After Surgical Removal of Cerebellar Tumor." JSHD, $31: 377-82,1966$.

Kirikae, E., Sato, T. and Shitara, T., "A Study of Hearing in Advanced Age." Laryngoscope, 74:205-20, 1964.

Korsan-Bengtsen, M., "Distorted Speech Audiometry." Acta Otolaryngol., Supp 1. 310, 1973.

Kryter, K.D., "Methods for the Calculation and Use of the Articulation Index." JASA, 34:1689-97, 1962a.

, "Speech Bandwidth Compression Through Spectrum Selection." JASA, $32: 547-56,1960$. 1702 , $1962 \mathrm{~b}$.

"Validation of the Articulation Index." JASA, 34:1698-

LaCroix, P.G. and Harris, J.D., "Effects of High-Frequency Cue Reduction on the Comprehension of Distorted Speech." JSHD, 44:236-46, 1979.

Liden, G., "Distorted Speech and Binaural Speech Resynthesis Tests." Acta 0tolaryngol., 58:32-48, 1964. 
Liden, G., "Undistorted Speech Audiometry." IN: Sensorineural Hearing Processes and Disorders, Graham, A.B. (Ed.), Boston: Little, Brown and Company, 1967.

Lundborg, T., Rosenhamer, J., Murray, T. and Zwetnow, N., "Information Abundance of Speech and Distorted Speech Testing in Topical Diagnos is Within the C.N.S." Scand. Aud., 4:9-16, 1975.

Maurer, J.F., Hicks, A. and Bowen, N.M., "A Test for Speech Discrimination Function Utilizing Frequency Specific Auditory Augmentation." Unpublished Research, Grant \#90-050-5801, Portland State University, 1981.

Orchik, D.J., Krygier, K.M. and Cutts, B.P., "A Comparison of the NU-6 and W-22 Speech Discrimination Tests for Assessing Sensorineural Hearing Loss." JSHD, 44:522-7, 1979.

Owens, E., "Intelligibility of Words Varying in Familiarity." USHR, $4: 113-29,1961$.

Palva, A., "Filtered Speech Audiometry." Acta Otolaryngol., Suppl. $210,1965$.

Pollack, I., "Effects of High Pass and Low Pass Filtering on the Intelligibility of Speech in Noise." JASA, 20:259-66, 1948.

Sanders, D.A. and Goodrich, S.J., "The Relative Contribution of Visual and Auditory Components of Speech to Speech Intelligibility as a Function of Three Conditions of Frequency Distortion." JSHR, $14: 154-9,1971$.

Schuknecht, H., Pathology of the Ear. Cambridge: Harvard University Press, 1974.

Schultz, M.C. and Streepy, C.S., "The Speech Discrimination Function in Loudness Recruiting Ears." Laryngoscope, 127:2114-27, 1967.

Sher, A.E. and Owens, E., "Consonant Confusions Associated with Hearing Loss Above $2000 \mathrm{~Hz}$." JSHR, 17, 669, 81, 1974.

Shirinian, M. and Arnst, D.J., "PI-PB Rollover in a Group of Aged Listeners." Ear and Hearing, 1:50-3, 1980.

Skinner, M.W., "Speech Intelligibility in Noise-Induced Hearing Loss: Effects of High Frequency Compensation." JASA, 67:306-17, 1980.

Snow, J.B., Rintelmann, W.F., Miller, J.M. and Konkle, D.F., "Central Auditory Imperception." Laryngoscope, 87:1450-71, 1977.

Stevens, J.H., "Monosyllabic Speech Tests." IN: Handbook of Clinical Audiology, Katz, J. (Ed.), Baltimore: The Williams and Wilkins Company, 1978. 
Tillman, T.W. and 01sen, W.0., "Speech Audiometry." IN: Modern Developments in Audiology, Jerger, J. (Ed.), New York: Academic Press, 1973 .

Wang, M.D., Reed, C.M. and Bilger, R.C., "Comparison of the Effects of Filtering and Sensorineural Hearing Loss on Patterns of Consonant Confusions." JSHR, 21:5-36, 1978.

Wegel, R.L. and Lane, C.E., "The Auditory Masking of One Pure Tone by Another and Its Probable Relation to the Dynamics of the Inner Ear." Phys. Rev., 23:266-85, 1924.

Welsh, 0.L., Luterman, D.M. and Bel1, B., "The Effects of Aging on Responses to Filtered Speech." J. of Gerontology, 24:189-92, 1969.

Willeford, J., "The Geriatric Patient." IN: Rose, D. (Ed.), Audiological Assessment, Englewood Cliffs: Prentice-Ha11, 1971. 